\title{
XV IMBG all-Ukrainian Conference of Young Scientists with international participation
}

\section{DNA fragmentation rate of goat spermatozoa after cryopreservation with egg yolk contained and egg yolk-free cryoprotective media}

\author{
A. O. Bogdaniuk, T. O. Yurchuk, M. P. Petrushko \\ Institute of Macromolecular Chemistry, NAS of Ukraine \\ 48, Kharkivske Shosse, Kyiv, Ukraine, 02160 \\ baa1995ua@gmail.com
}

Introduction. DNA integrity of spermatozoa is crucial for oocyte fertilization and normal embryo development. However, many factors during cryopreservation such as centrifugation, equilibration with cryoprotectant, freezing and thawing may cause DNA fragmentation. Aim. The aim of this study was to evaluate DNA fragmentation of goat spermatozoa after cryopreservation with different cryoprotective media in non-breeding season. Methods. 15 ejaculates from 5 sexually matured goats were obtained during non-breading season (January-March). Immediately after collection, total concentration of spermatozoa, motility and viability were calculated. DNA fragmentation of spermatozoa was evaluated using Halosperm kit (Halotech DNA, Spain). Each ejaculate was split into 4 groups. Groups 1 and 2 were diluted with HEPES based media supplemented with $10 \%$ glycerol, groups 3 and 4 were diluted with HEPES based medi a supplemented with $10 \%$ glycerol and $20 \%$ egg yolk. Extended semen of each group was equilibrated $15 \mathrm{~min}$ at room temperature $\left(25^{\circ} \mathrm{C}\right)$ and loaded into $0.25 \mathrm{~mL}$ straws (Minitube, Germany). Then the samples of groups 1 and 3 were equilibrated for $30 \mathrm{~min}$ at $5^{\circ} \mathrm{C}$, while [the]samples of groups 2 and $4-$ for $2.5 \mathrm{~h}$ at $5^{\circ} \mathrm{C}$. The straws of all groups were placed horizontally $4 \mathrm{~cm}$ above liquid nitrogen for $15 \mathrm{~min}$ and plunged into the liquid nitrogen. Thawing was performed on a water bath at $37^{\circ} \mathrm{C}$ for $30 \mathrm{~s}$. Cryoprotectant was removed by centrifugation at $1500 \mathrm{rpm}$ for $5 \mathrm{~min}$ with $2 \mathrm{~mL}$ washing media. Sperm motility, viability and DNA fragmentation were evaluated after thawing and removing cryoprotectants. Results. Cryopreservation caused a significant $(p \leq 0.05)$ decrease of the sperm motility and viability and an increase of DNA fragmentation rate. Group 1 showed the lowest sperm motility and viability and the highest rate of DNA fragmentation. The highest DNA integrity, kinetic characteristics and viability of spermatozoa were obtained in group 4. There was no significant difference of evaluated parameters between groups 2 and 3. Conclusions. Cryoprotective medium with $10 \%$ glycerol and $20 \%$ egg yolk preserves goat spermatozoa (DNA integrity, motility, and viability) better than cryoprotective medium with glycerol only. 


\title{
Impact of immobilization of landomycin a on poly-2-oxazoline carrier on therapeutic effect of the antitumor antibiotic toward mice with B16F10/wt melanoma
}

\author{
Yu. S. Kozak, N. R. Skorokhyd, R. P. Panchuk, R. S. Stoika \\ Institute of Cell Biology, NAS of Ukraine \\ 14/16, Drahomanov Str., Lviv, Ukraine, 79005 \\ juliana.kozzak@gmail.com
}

Introduction. The main aim of modern chemotherapy is to search for and implement new effective drugs in medical practice. The results of our previous studies indicate that a promising candidate is the antitumor antibiotic landomycin A (LA). The problem is that LA is insoluble in aqueous solutions, which complicates its use for in vivo experiments. To solve the above disadvantage, a water-soluble complex of landomycin A with poly-2-oxazoline carrier was created. The aim of this work was to study and compare the therapeutic effect of the experimental antitumor agent landomycin A and the water-soluble complex of this antibiotic with poly-2-oxazoline nanocarrier against B16F10/wt melanoma in mice. Methods. Survival analysis of tumor-bearing mice, investigation of tumor volume change by measuring their size with a caliper every 72 hours from the 10th day after inoculation of B16F10/wt melanoma. A tumor volume was calculated by the formula: $1 / 2 \times$ length $\times$ width $\times$ height. Study of hematological parameters of the tumor-bearing mice on the 30th day after tumor inoculation using an automated hematology analyzer Dymind DF51. Results. The volume of this work was quite large so it was divided into several stages. In the first phase of this study, the effect of LA and its complex with $\mathrm{NC}$ on the survival, tumor volume, and hematological blood profile of mice with B16F10/wt melanoma was studied. The maximum tumor volume in animals administered with $\mathrm{LA}+\mathrm{NC}$ was $514.5 \mathrm{~mm}^{3}$. Noteworthy, it is 5.4 times less than the value of this indicator in mice injected with only LA. The treatment of mice with $\mathrm{NC}$ alone did not slow down the growth of B16F10/wt melanoma and its volume on the 28th day of the experiment was 4400 $\mathrm{mm}^{3}$. The rate in untreated mice was $4800 \mathrm{~mm}^{3}$. The survival of mice with B16F10/wt melanoma was 30-40 days after tumor inoculation. The treatment of animals with NC only had no effect on their life expectancy. The treatment of mice with only Dx or LA increased their life expectancy on average by 1.3 times, but no animal survived to the end of the experiment (the experiment duration was 120 days). Administration of $\mathrm{LA}+\mathrm{NC}$ to animals increased their survival three-fold compared to the lifespan of untreated mice with B16F10/wt melanoma. Thus, all animals in this experimental group lived for more than 120 days. The use of LA in complex with $\mathrm{NC}$ toward the mice with $\mathrm{B} 16 \mathrm{~F} 10 / \mathrm{wt}$ melanoma leads to normalization of the number of erythrocytes, platelets, segmented neutrophils, small lymphocytes and content of hemoglobin in the blood of experimental mice to the level characteristic of healthy animals. Conclusion. It was found that immobilization of landomycin A on a poly-2-oxazoline nanocarrier leads to an increase in the therapeutic potential of this antitumor antibiotic toward the mice with melanoma B16F10/wt. 


\title{
Rapid mycotoxins monitoring systems in cereals using smartphone- based biomimetic sensor
}

\author{
D. V. Yarynka ${ }^{1}$, I. Ya. Dubey ${ }^{1}$, L. V. Dubey ${ }^{1}$, E. V. Piletska ${ }^{2}$, Ye. Yu. Stepanenko ${ }^{1}$, \\ R. P. Linnik ${ }^{3}$, M. Z. Antonyuk ${ }^{4}$, O. O. Brovko ${ }^{5}$, S. A. Piletsky ${ }^{2}$, T. A. Sergeyeva ${ }^{1}$ \\ ${ }^{1}$ Institute of Molecular Biology and Genetics, NAS of Ukraine \\ 150, Akademika Zabolotnoho Str., Kyiv, Ukraine, 03143 \\ 2 University of Leicester \\ University Road, Leicester LE1 7RH, UK \\ ${ }^{3}$ Taras Shevchenko National University of Kyiv \\ 64, Volodymyrska Str., Kyiv, Ukraine, 01601 \\ ${ }^{4}$ National University of Kyiv-Mohyla Academy \\ 2, Skovorody Str., Kyiv, Ukraine, 04655 \\ 5 Institute of Macromolecular Chemistry, NAS of Ukraine \\ 48, Kharkivske Shosse, Kyiv, Ukraine, 02160 \\ daria.yarinka@gmail.com
}

\begin{abstract}
Aim. This study describes smartphone-based fluorescent sensor systems capable of rapid and accurate contamination monitoring of most prevalent mycotoxins - aflatoxin B1 (AFB1) and zearalenone (ZON) in cereals using biomimetic polymers as highly sensitive, cost-effective elements for mycotoxin recognition. Methods. Biomimetic polymers in the form of free-standing molecularly imprinted polymer (MIP) membranes were synthesized using the technique of molecular imprinting and method of in situ polymerization. Ethyl-2-oxocyclopentanecarboxylate and cyclododecyl-2,4dihydroxybenzoate - non-toxic and non-fluorescent close structural analogues of AFB1 and ZON, respectively, were used as dummy templates. Functional monomers were chosen using the results of computational modeling. The $60 \mu \mathrm{m}$-thick MIP polymeric membranes were obtained using UV-irradiation conducted during $30 \mathrm{~min}$ (Sergeyeva et al. 2017). The fluorescent sensor response associated with the AFB1 and ZON binding to the MIP membrane surface were registered by the smartphone camera (Meizu 16, 20 MP, F/1,8) after 1 min excitation with UV-irradiation. Smartphone application Spotxel ${ }^{\circledR}$ dependencies of fluorescence intensity on the toxin concentration in the sample within real time. Results. MIP membranes that mimic the receptors towards AFB1 and ZON were synthesized and used as sensing elements in smartphone-based biomimetic sensor. The critical parameters of analyzed sample, including $\mathrm{pH}$, buffer concentration, salt addition, that can affect the recognition properties of the MIP membranes, were investigated and optimized. The working parameters of the sensors systems for AFB1 and ZON detection were further analyzed. The MIP membranes with the optimized composition can successfully discriminate between an analyte of interest (AFB1 or ZON) and its close structural analogues (AFB2, AFG2, OTA, zearalenol, 17- $\beta$-estradiol, bisphenol A, resorcinol). The limits of detection (LOD) as well as linear detection ranges were determined. The aflatoxin $\mathrm{B} 1$ detection limit was established to be $15 \mathrm{ng} / \mathrm{ml}$ and the working range $15-500 \mathrm{ng} / \mathrm{ml}$. The ZON-specific MIP membrane-based sensor system showed LOD of ZON detection $1 \mu \mathrm{g} / \mathrm{mL}$, the linear detection range was $1-10 \mu \mathrm{g} / \mathrm{mL}$. The proposed sensing elements remain stable at room temperature for 18 months. Using the smartphone-based biomimetic polymers sensor systems, AFB1 and $\mathrm{ZON}$ were quantitatively detected in the spiked wheat, rye and maize flour samples along with the naturally contaminated wheat and maize. Conclusions. The MIP membrane-based sensor systems were designed and used for monitoring the most common mycotoxins - AFB1 and ZON in cereals using smartphone as detector and quantifier. The proposed smartphone-based sensor systems provide a promising technique for highly sensitive, on-site monitoring of mycotoxin contamination and personalized food safety. Acknowledgement. Financial support from National Academy of Sciences of Ukraine.
\end{abstract}




\title{
ATP content in tissues under the influence of IL-2 during physical training
}

\author{
V. A. Shvets \\ Kherson State University \\ 27, Universytets'ka Str, Kherson, Ukraine, 73000 \\ shvetsvika88@gmail.com
}

Background. Functional shifts occur in various body systems during physical training, as well as at other types of the stress (Magherini et al., 2019; Wang et al., 2020). Exercises disrupt homeostasis, change the level of circulating mediators and hormones, increase the need of skeletal muscles and other vital organs in energy substrates. The fatigue after physical training is caused by depletion of energy substrates (creatine phosphate, ATP and glycogen) in tissues with further accumulation of products of their metabolism in the blood (creatine, lactic acid and inorganic phosphates) (Lombardi et al., 2020). Therefore, the change of these indicators is important to evaluate how the body adapts to exercises in different physiological conditions. The aim of the study was to investigate the effect of interleukin-2 (IL-2) and its inhibitor on the content of ATP in the tissues of white mice during physical training. Methods. Research groups were formed. For 6 weeks, the experimental animals received subcutaneously the drug IL-2 and orally its inhibitor Cyclosporine. Group I of animals was injected with an inhibitor of IL-2 (10 mg / kg), II, III and IV - IL-2 in concentrations of 5000, 7500 and 30,000 IU/kg, $\mathrm{V}$ - saline, control - without the influence of drugs and physical activity. Forced swimming with load was used as physical training. The tissues (liver and muscles) were isolated in the cold, washed from the blood with chilled saline. In the prepared homogenates, the ATP content was determined by spectrophotometric method]. Results. The study of the ATP content in homogenates of the liver and the muscles of experimental animals during physical training showed that at the $2^{\text {nd }}$ week in all experimental groups of animals the indicators (both in muscles and liver) were lower than in control group. The ATP content in liver decreased from $14.5 \%$ to $34.9 \%$, the lowest rate was observed in II ( $8.94 \mu \mathrm{mol} / \mathrm{g}$ tissue $)$, and the highest in III $(11.74 \mu \mathrm{mol} / \mathrm{g}$ tissue $)$ experimental groups. In muscles, the concentration of ATP decreased from $21.5 \%$ to $41.4 \%$, with the lowest values in IV and V groups of animals - 3.52 and $3.64 \mu \mathrm{mol} / \mathrm{g}$ of tissue, respectively. At the $4^{\text {th }}$ week of the experiment, the content of ATP in muscles increased in I, III and V (by $9.7 \%, 21.5 \%, 13.2 \%$, respectively) and decreased in II and IV (by $24.6 \%$ and $13.6 \%$, respectively) groups of animals relative to the previous period. During this period, the concentration of ATP in liver decreased only in Group V (by $13.6 \%$ ) and increased in all other groups of animals (from $13.5 \%$ in Group III to $50.6 \%$ in Group II) compared with the $2^{\text {nd }}$ week of the experiment. At the $6^{\text {th }}$ week (at the end of the experiment), compared with the $4^{\text {th }}$ week of the study, the ATP content in liver increased only in Group V, and decreased in Groups I-IV from $2.5 \%$ to $11.9 \%$. However, the concentration of ATP in liver during the experiment was lower than in control group. During this period, the concentration of ATP in muscles of experimental animals decreased only in IV and increased in I-III and $\mathrm{V}$ groups compared to the previous period. Noteworthy, the indicators of Group III almost did not differ from the level of control, i.e. the normalization of in energy metabolism occurs. Conclusion. Therefore, IL-2 had a different effect on the ATP concentration in tissues depending on the IL-2 concentration and duration of its administration. It may be considered as one of the indicators of adaptive processes in tissues during physical training. 


\title{
Transient expression of reporter genes in seedlings of helianthus Annuus L.
}

\author{
O. M. Yaroshko \\ Institute of Cell Biology and Genetic Engineering, NAS of Ukraine \\ 148, Akademika Zabolotnogo Str., Kyiv, Ukraine, 03680 \\ 90tigeryaroshko90@gmail.com
}

Introduction. Sunflower (Helianthus annuus) is a valuable oilseed crop. Due to the peculiarities of the biochemical composition, the regeneration process of these plants is quite complicated. In this regard, it is necessary to use such methods of genetic transformation that will not require obtaining of regenerants. One of such methods can be the method of Agrobacteriummediated transformation, which results in the transient gene expression. The aim of the experiments was to confirm the possibility of transient expression of the reporter genes gus and $g f p$ in seedlings of Helianthus annuus. Methods. Following methods were used in the experiments: Agrobacterium-mediated transformation (with the help of vacuum infiltration), biochemical methods (histochemical assay), visual observation, microscopy of plant tissues, statistical methods. The object of investigation was the variety of local breeding Sonechko, Helianthus annuus L. First, seeds were sown in the pots with soil and grown in the greenhouse under the conditions $22-26^{\circ} \mathrm{C}, 14$-hour light period, illumination $-3000-4500 \mathrm{~lx}$. Young seedlings of Helianthus annuus ( 1 day-old and 10 day-old) were infiltrated with agrobacterial suspensions under the pressure $0.1 \mathrm{mPa}$ in the vacuum chamber for 5-10 $\mathrm{min}, 22-24{ }^{\circ} \mathrm{C}$. In the work the strains GV3101 of $A$. tumefaciens with pCBV19 and pNMD2501genetic vectors (separately) were used. Genetic vector pCBV19 carried gus gene and genetic vector pNMD2501 carried $g f p$ gene. For detection of the $\beta$-glucuronidase activity (gus gene expression), histochemical staining was conducted at $370^{\circ} \mathrm{C}$ according to Jefferson on the 6th day after infiltration of seedlings. The $\beta$-glucuronidase activity was detected visually by the appearance of blue staining of the transformed plant tissues. The detection of the gfp gene expression was conducted visually by the green fluorescence of infiltrated tissues under blue rays (wavelength of $365 \mathrm{~nm}$ ) on the $4^{\text {th }}$ till $12^{\text {th }}$ days after infiltration. The results of histochemical staining were positive for $30 \%$ of 10 day-old plants and $41.6 \%$ of 1 day-old plants out of the total quantity of infiltrated seedlings. The areas with green fluorescence on the cotyledon leaves were observed after infiltration of $A$. tumefaciens with the genetic vector pNMD2501, maximum expression was detected on the $6^{\text {th }}$ day on the upper edge of the leaves. Conclusions. According to the obtained results, we can state that seedlings of variety Sonechko of $H$. annuus are susceptible for transformation with A. tumefaciens, and it is possible in the future to transform seedlings of $H$. annuus with genetic vectors of $A$. tumefaciens, which will carry not only the reporter genes but also the target genes. 


\title{
Spectral studies on oligoribonucleotides and their components at room temperature
}

\author{
Ye. Yu. Stepanenko, Z. Yu. Tkachuk, R. O. Nikolaiev \\ Institute of Molecular Biology and Genetics, NAS of Ukraine \\ 150, Akademika Zabolotnoho Str., Kyiv, Ukraine, 03143 \\ stepanenkojack@gmail.com
}

Introduction. Spectral methods of analysis are usually faster and cheaper than biological, require fewer test samples and do not destroy them. For the study of oligoribonucleotides, fluorescent methods usually used at low temperatures (77 K (liquid nitrogen), $4 \mathrm{~K}$ (liquid helium)). However, low-temperature research is very expensive and time-consuming and requires special equipment. Thus, the aim of our study was to develop relatively cheap, fast, and affordable methods for analyzing the flow of samples for the presence/absence of nucleic acids at room temperature $\left(293 \mathrm{~K} / 20^{\circ} \mathrm{C}\right)$. Methods. We measured the absorption, fluorescence, and excitation spectra of fluorescence of samples in the form of powder and dissolved in water at room temperature. UV-VIS absorption spectra were recorded using a two-beam spectrophotometer Specord 210 Plus (Analytik Jena). Spectral fluorescence and fluorescence excitation were recorded at room temperature using a Fluoromax-Plus spectrofluorimeter (HORIBA Instruments Inc.) and an FP-8200 Fluorescence Spectrometer (JASCO). For aqueous solutions, we used degassed ddH2O. Results. Oligoribonucleotides and their derivatives were investigated using fluorescent methods. Adenosine, guanosine, cytosine, uridine, and inosine were investigated and identified on 3D excitation/emission spectra. The results are compared with aromatic amino acids and proteins. A method was developed to analyze samples for the presence/absence of nucleic acids at room temperature. The 3-D excitation/emission matrix is divided into zones according to proteins $(200-275$ / 250-360 nm), nucleic acids $(250-375 / 300-500 \mathrm{~nm})$ and lipids $(350-500 / 450-550 \mathrm{~nm})$ derivatives. The points on the spectrum were chosen, in which there is no influence of other components. Conclusions. We registered the fluorescence of oligoribonucleotides and their components at room temperature. At T $>273.15 \mathrm{~K}$ it is possible to register and identify the fluorescence of individual nucleotides. Checking at room temperature the "purity" of the samples for the presence/absence of nucleic acids and their residues is quickly enough. In samples containing all or fewer components (proteins, lipids, nucleic acids), each and/or their residues can be identified separately. 


\title{
DNA fragmentation level as apoptosis marker in human spermatozoa in different states of spermatogenesis
}

\author{
N. O. Shapovalova ${ }^{1}$, T. O. Yurchuk ${ }^{1}$, O. V. Pavlovich ${ }^{1}$, G. O. Gapon ${ }^{1}$, M. P. Petrushko² \\ ${ }^{1}$ Institute for Problems of Cryobiology and Cryomedicine, NAS of Ukraine \\ 23, Pereyaslavskaya Str., Kharkiv, Ukraine, 61015 \\ ${ }^{2}$ ART Clinic of Reproductive Medicine \\ 38 Gagarin Avenue, Kharkiv, 61000 \\ ntshpvlva@gmail.com
}

Introduction. Sperm DNA fragmentation is considered as one of the factors of male infertility. The connection between violations of the organization of the genetic material of male germ cells with infertility is a general problem, both biological and medical. Culling sperm with abnormalities in the organization of the genetic material is important to prevent serious abnormalities in embryonic development. Normally, DNA must have a certain conformation, chemical and physical structure, so any minor damage to DNA or a violation of its packaging can lead to an incorrect development of events after fertilization. The presence of DNA breaks may reflect the course of apoptosis - genetically programmed cell death. The aim of our work was to establish the level of DNA fragmentation in men spermatozoa with different states of spermatogenesis. Methods. The study group included 84 male ejaculates: group 1 - normozoospermia $(n=40)$, group 2 - oligoasthenoteratozoospermia $(n=30)$, group 3 - azoospermia $(n=14)$, while spermatozoa were obtained from the testes or their appendages. DNA fragmentation was determined by the HaloSperm method (Halotech, Spain). Results. DNA fragmentation level in spermatozoa of group 1 was $(8.9 \pm 1.6) \%$. This indicator more than doubled and amounted to $(21.7 \pm 9.3) \%$ in men with low morphological and functional characteristics of the ejaculate (group 2). In the case of azoospermia, in which spermatozoa were aspirated from the testis or its epididymis, the frequency of DNA abnormalities was (5.3 \pm $1.2) \%$. Conclusions. The DNA fragmentation index in human spermatozoa obtained from the ejaculates of men with normozoospermia is significantly lower $(p<0.01)$, compared with this indicator in oligoasthenoteratozoospermia. The minimum value of this indicator was found in epididymal and testicular spermatozoa $(\mathrm{p}<0.001)$. Thus, with high values of the DNA fragmentation index in ejaculatory spermatozoa, it is advisable to use epididymal or testicular spermatozoa for further fertilization. 


\title{
The impact of metformin and vitamin $D$ on the protein profile of rat kidney under the condition of type 2 diabetes and intracerebral hemorrhage
}

\author{
Y. V. Murdasov ${ }^{1}$, V. I. Zhilyuk², G. A. Ushakova ${ }^{1}$ \\ ${ }^{1}$ Oles Honchar Dnipro National University \\ 72, Gagarin Av., Dnipro, Ukraine, 49050 \\ 2 Dnipro State Medical University \\ 9, Volodymyra Vernadskoho Str, Dnipro, 49044 \\ mr.muradasu@gmail.com
}

Introduction. The normal protein ratio is important for cell function. Diabetes mellitus type 2 (DM2) and intracerebral hemorrhage (ICH) may change the protein profile of kidney cells due to the harmful action of high glucose level, oxidative stress, and systemic inflammation. This may lead to protein damage, kidney hypertrophy, and renal function declining. The aim of this work is to observe the effect of metformin and vitamin $\mathrm{D}$ on the protein profile of rat kidneys under the condition of DM2 and ICH. Methods. The studies were performed on adult male Wistar rats in accordance with the ethical standards of work with laboratory animals. All rats were divided into 5 groups $(\mathrm{n}=6)$ : 1 - control group; 2 - rats with experimental streptozotocin-induced DM2; 3 - rats with DM2 and ICH; 4 - rats with DM2 and ICH under metformin administration; 5 - rats with DM2 and $\mathrm{ICH}$ under vitamin D administration. All measurements were done in the cytosolic fraction, obtained from rat kidneys homogenates. The quantitative protein assay was performed by using the Bradford method, the qualitative protein assay was performed by using SDS-PAGE by the Laemmli method, for densitometry we used GelAnalyzer soft. Results. We have observed a mild decrease of total protein (TP) values in the 2nd and especially 3rd experimental group relatively to the control group. This decrease in TP values could be explained by proteolysis and hyperfiltration in the DM2 condition. Metformin and vitamin D usage slightly improved the mean TP values in the 4th and 5th groups, increasing it to the values of the control group. At the same time, assessing the ratio of proteins in rat kidneys, we observed an elevated content of proteins with high molecular weight in the 2nd and especially 3rd group comparing to the control group. On the other hand, the content of low molecular proteins in the 2nd and 3rd groups decreased compared to the control group. All this could be explained by the action of reactive oxygen species in the condition of $\mathrm{DM} 2$ and $\mathrm{ICH}$, protein deconstruction and protein conglomerates formation, depletion of cell stores, and inflammation. Metformin and vitamin D usage improved the protein ratio in the 4 th and 5 th groups, turning it closer to the control group. Conclusion. DM2 and ICH can affect renal function, and the occurrence of ICH under condition of DM2 may worsen the kidney protein profile. High glucose levels in DM2 lead to elevated oxidative damaging of tissues and ICH causes systemic inflammation in organism. Oxidative stress and general inflammation may be the reasons for renal impairment and renal function declining, which may eventually lead to chronic kidney disease. The administration of vitamin D and metformin improved the protein profiles of rat kidneys at DM2 and ICH. 


\title{
Investigation of protective action of "Mixfactor's" immunotropic dietary supplement on an experimental model of animals, immunized with pathogenic sera
}

\author{
H. Ye. Tsapko, A. R. Logvynova, M. S. Taranushych, Ye. H. Kostenko \\ V. N. Karazin Kharkiv National University \\ 4, Svobody Ave., Kharkiv, Ukraine, 61077 \\ getsapko@gmail.com
}

Introduction. Bioactive supplements development and evaluation of their immunotropic action are of great interest nowadays. These compounds successfully compete with immunotropic growth factors and cytokines, which are produced using the recombinant DNA method. Aim. To develop the experimental model of animals, immunized with polyvalent splenomegaly patients' immunogenic sera, for studying the protective action of the "Mixfactor" bioactive compound. Methods. To create the model, pathogenic sera from patients with splenomegaly were examined for the content of immunogenic factors: oligopeptides and nucleotides. Serum A was enriched with oligopeptides, serum B - with nucleotides. Animals (3-month-old rats) were divided into 6 groups. The degree of immunogenicity of sera A and B for experimental animals was estimated with lymphocytotoxicity test, bioindication using the Dunaliella viridis cell test system, and oxygen-independent phagocytosis rate evaluation. Complex rat's neutrophils phagocytosis activity assay was done by coloring them with acridine orange and subsequent assessment of engulfed microorganisms DNA denaturation by its color change from green to red. Phagocytic index, active phagocytes number, and phagocytosis completion index were determined. Results. It was shown that the composite bio-supplement "Mixfactor" has immunomodulating effect and, possibly, induces the synthesis of low molecular adapter proteins, but prevents autoantibodies formation. Thus, as a result of immunization with A and B sera, lymphocytotoxicity increased to $31 \%$ and $51 \%$ respectively. For the animals that received "Mixfactor" before immunization preventively, this indicator was at the control level $(19.7 \%)$. This test showed that the preventive action of the "Mixfactor" reduces the number of autoantibodies. Integral cytotoxicity test with $D$. viridis bioindicator showed no difference between the control and comparison groups, and "Mixfactor" preventive action followed by animals' immunization with pathogenic sera A and B increased the cytotoxicity coefficient due to immunogenic factors creation and activation of cytotoxic T-killer cells after immunization with serum A - by $10 \%$, serum B - by $8 \%$. Compared to the control, the indicators of phagocytosis were lower in all experimental groups. "Mixfactor" preventive administration increased the phagocytic index, phagocytosis completion index of non-immunized animals, and active phagocytes number in all groups, compared to the corresponding groups, which did not receive "Mixfactor". Conclusions. "Mixfactor" bioactive compound,

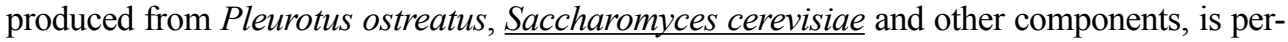
spective immunotropic agent, which can be used for the correction of the immune system's indicators. 


\title{
Study on copper accumulation and distribution in cells of Dunaliella viridis superproducer culture
}

\author{
O. O. Shlakhter, M. K. Kovalova, S. S. Haiovyi \\ V. N. Karazin Kharkiv National University \\ 4, Svobody Ave., Kharkiv, Ukraine, 61077 \\ wiortimnein@gmail.com
}

Introduction. It is known that copper is an essential microelement that influences Fe metabolism; copper deficiency leads to anemia (Myint, 2018). However, using salts of heavy metals to overcome the deficiency is dangerous because of toxic effects on the organism (Stern, 2007). A promising solution is the use of microalgae superproducers biomass with high copper content, particularly Dunaliella genus. As a result of adaptive screening, a $D$. viridis strain, which is able to grow in the presence of lethal for this species $\mathrm{CuSO}_{4} \times 5 \mathrm{H}_{2} \mathrm{O}$ concentration $(75 \mathrm{mg} / \mathrm{L})$, was obtained. The aim is to estimate the growth, morphology, accumulation and distribution of copper in the cells of resistant and sensitive to high copper concentrations $D$. viridis cultures, as well as in the cells of resistant culture after transfer to pure medium (with no copper addition). Methods. Investigated: sensitive $(\mathrm{CuS})$, resistant $(\mathrm{CuR})$ cultures and resistant culture grown on pure medium in the first passage (CuR-). Cultivation was performed on Artari medium (with the addition of $\mathrm{CuSO}_{4} \times 5 \mathrm{H}_{2} \mathrm{O}$ to to obtain $75 \mathrm{mg} / \mathrm{L}$ final concentration for $\mathrm{CuR}$ ) for 21 days in $20 \mathrm{ml}$ flasks; the initial concentration of cells was $1.3 \times 10^{6}$ cells $/ \mathrm{ml}$. Morphological and biochemical parameters were determined after 21 days. The cell fractions were separated by differential centrifugation, and the copper concentration was determined by atomic absorption spectrophotometry. Results. There was a decrease in $\mathrm{CuR}$ growth relative to control in the initial stages (up to 5 days); then the cell concentrations were equal; the growth curve of $\mathrm{CuR}$ corresponded to CuS. Morphologically, $\mathrm{CuR}$ and $\mathrm{CuR}$ - contained by $30 \%$ more round cells than in the control. The copper content in the CuR culture cells was 121 times higher than in the CuS culture cells. In the CuR culture cells, copper ions in the cytosol were 1.6 times less than in the control $(\mathrm{CuS})$, and in the nuclear fraction 15 and 3 times more (in the membrane and the karyoplasm, respectively). In the CuR - culture cells, the content of copper ions decreased in comparison with the CuR culture, which indicates the copper ions removal from the cells. Thus, the content of total copper in cells decreased 11 times, in the cytosol -2.9 times, and in the nuclear fraction (in the karyoplasm) -2.8 times, respectively, but was higher than in the cells of the CuS culture (except the cytosolic fraction). Conclusions. It was shown that the $\mathrm{D}$. viridis culture is able to adapt and grow under the high copper content $\left(75 \mathrm{mg} / \mathrm{L} \mathrm{CuSO}_{4} \times 5 \mathrm{H}_{2} \mathrm{O}\right)$ in the environment. This culture has morphological and biochemical features and can accumulate copper in high concentrations compared to the control. When transferred to a pure medium, the copper content decreases significantly in all fractions (disproportionately), but morphological features are preserved. It makes CuR culture a potential source of copper in the deficiency of this element. 


\title{
NADH:ubiquinone reductase activity in kidneys of rats under different nutrition supplies
}

\author{
M. S. Ursatyi, O. M. Voloshchuk, G. P. Kopylchuk \\ Yuriy Fedkovych Chernivtsi National University \\ 2, Kotsjubynskyi Str., Chernivtsi, Ukraine, 58012 \\ ursatyi.mariia@chnu.edu.ua
}

Introduction. The issue of food security is one of the main global problems of mankind, as malnutrition is considered to be one of the determining factors in the development of a number of metabolic disorders. The question of the mechanisms of formation of metabolic disorders in the kidneys under conditions of nutritional imbalance has become especially relevant. The functional activity of the kidneys is largely determined by the efficiency of the energy supply system. Therefore, the aim of work was to study the NADH-ubiquinone reductase activity (CF 7.1.1.2), the total content of ubiquinone and the intensity of oxidative modification of proteins in the mitochondria of the kidneys of rats under conditions of different nutrient supply. Methods. Four groups of animals were used in the studies: I - control; II — animals kept on a low-protein diet; III — animals kept on a high-sucrose diet; IV — animals kept on a low-protein/high-sucrose diet. Results. The results of the study showed that under conditions of consumption of low-protein diet, in the mitochondria of the rat kidneys a decrease in the NADH-ubiquinone reductase activity was observed. In contrast, an increase in the NADHubiquinone reductase activity was registered under the conditions of keeping animals on a high-sucrose diet. It is known that hyperglycemia increases the need for ATP required for reabsorption of glucose in the proximal tubules of the kidneys, and leads to intensification of oxidative phosphorylation. At the same time, the most pronounced changes were registered in the animals that consumed a low-protein/high-sucrose diet, in particular, there was almost twice decrease in the NADH-ubiquinone reductase activity compared to the control. It is shown that in the mitochondria of the kidneys of rats under conditions of consumption of low-protein diet, there is a slight decrease in total ubiquinone. However, the most pronounced decrease in total ubiquinone was recorded in the animals that consumed a low-protein/high-sucrose diet. As a result of the research it is shown that under the conditions of keeping animals on a lowprotein diet in the mitochondrial proteins of the kidneys of rats no increased accumulation of carbonyl derivatives is observed, but the content of free SH-groups is significantly lower compared to control. At the same time, under the conditions of keeping animals on a lowprotein/high-sucrose diet, the most pronounced intensification of free radical damage of mitochondrial proteins is observed, in particular, an increase in the content of carbonyl derivatives was recorded twice as compared to the control. Conclusions. Thus, excessive consumption of sucrose on the background of protein deficiency is accompanied by a decrease in the NADHubiquinone reductase activity and total ubiquinone on the background of intensification of free radical damage of mitochondrial proteins, which can be considered as a prerequisite for the of development of the kidney mitochondrial dysfunction. 


\title{
Activity of heme metabolism enzymes in the kidneys under different nutrient supplies
}

\author{
Z.-M. I. Hrynenkiv, O. M. Voloshchuk \\ Yuriy Fedkovych Chernivtsi National University \\ 2, Kotsjubynskyi Str., Chernivtsi, Ukraine, 58012 \\ hrynenkiv.zoriana-mariia@chnu.edu.ua
}

Introduction. Today, the study of the effect of unbalanced nutrition on metabolic processes in the body remains relevant. The kidneys are among the most metabolically active organs, rich in mitochondria. Disruption of the energy supply processes in mitochondria leads to tubular dysfunction, which is considered to be one of the main causes of the emergence and progression of many kidney diseases. It is known that the kidneys intensively produce ATP, which is necessary to ensure biosynthetic processes, the release of end products of metabolism, reabsorption, maintenance of electrolyte and water-salt balance. Therefore, the question of the mechanisms of energy homeostasis disturbance, which may result in changes in the functional activity of the kidneys, under conditions of nutritional imbalance remains open. Our work aims to study the activity of key enzymes of heme metabolism in the mitochondrial fraction of rat kidneys under low-protein, high-sucrose, low-protein/high-sucrose diets. Methods. The quantitative determination of mitochondrial cytochrome was performed by differential spectrophotometry. The $\delta$-aminolevulinate synthase activity was determined spectrophotometrically taking into account the molar extinction coefficient of $0.023 \times 10^{3} \mathrm{~mol}^{-1} \times \mathrm{cm}^{-1}$. The hemoxygenase activity was determined by the amount of bilirubin formed and expressed as nmol of bilirubin per $1 \mathrm{mg}$ of protein per 1 minute. Results. It was found that in the mitochondria of the kidneys of animals that consumed a low-protein diet, the activity of $\delta$-aminolevulinate synthase and hemoxygenase does not change significantly compared to the control. At the same time, under the conditions of keeping animals on a diet containing an excess of sucrose, a decrease in the activity of $\delta$-aminolevulinate synthase is observed against the background of an increase in the hemoxygenase activity. A similar trend is observed in the mitochondrial fraction of the kidneys of rats kept on a diet with simultaneous protein deficiency and excess sucrose. Noteworthy, under the studied experimental conditions a decrease in the content of all mitochondrial cytochromes, with the most pronounced changes in the content of mitochondrial cytochromes was recorded in the animals that consumed a low-protein/high-sucrose diet. Thus, excessive consumption of sucrose against the background of protein deficiency is accompanied by a decrease in the $\delta$-aminolevulinate synthesis against the background of increased hemoxygenase activity, resulting in changes in the functional activity of the cytochrome region of the respiratory chain with subsequent formation of energy deficiency and energy disorders. Conclusions. The established changes in the content of mitochondrial cytochromes, $\delta$-aminolevulinate synthase, and hemoxygenase activity in the kidneys can be considered as prerequisites for deepening their energy imbalance under conditions of different supply of sucrose and protein, which in turn can lead to progression of kidney damage. 


\title{
Intensity of superoxide anion-radical generation by blood lymphocytes of uterine corpus cancer patients at small doses of radiation in vitro
}

\author{
O. O. Hrinchenko ${ }^{1}$, D. O. Ratsun ${ }^{1}$, E. A. Domina ${ }^{1}$, V. S. Ivankova ${ }^{2}$ \\ ${ }^{1}$ R. E. Kavetsky Institute of Experimental Pathology, Oncology and Radiobiology, NAS of Ukraine \\ 45, Vasilkivska Str., Kyiv, Ukraine, 01022 \\ 2 National Cancer Institute \\ 33/43, Lomonosova Str., Kyiv, Ukraine, 03022 \\ griniolia@gmail.com
}

Introduction. The main treatment method for the uterine corpus cancer (UCC) patients is radiation therapy. Reasonable concern is caused by complications for healthy tissues caused by the environment of the irradiated tumor. Therefore, the study of radiosensitivity predictors of the UCC patients healthy cells, based on the dose-effect relationship is relevant and should contribute to the personification of radiation therapy. The intensity of superoxide anion radical (SAR) generation, which is a starting factor of free radical processes during radiation is considered as one of main parameters (Druzhyna M., 2020). Aim. To investigate the intensity of SAR generation by peripheral blood lymphocytes of primary UCC patients at small doses of radiation in vitro. Materials and methods. The investigation was carried out on the basis of the blood samples from primary UCC patients using lucigenin indicator and chemiluminescent method of estimating the rate of SAR generation. Blood samples were irradiated in vitro on an X-ray device in the dose range $0.1-0.5$ Gy and dose rate of $0.55 \mathrm{~Gy} / \mathrm{min}$. Results: We established that at the beginning of radiation therapy, an intensity of SAR generation by the UCC patient's blood lymphocytes increase and corresponds to the average intensity of this indicator. In our opinion, the advancement of the SAR generation by blood lymphocytes of primary UCC patients testifies to the systemic inflammation, which usually accompanies the carcinogenesis processes. For the first time it was established that the greatest value of SAR biochemical indicator is noted during irradiation in dose of 0.1 Gy and that it exceeds the value of similar indicator of healthy donors blood lymphocytes by 1.4 times. With an increase in the radiation dose the curve comes to plateau. The same picture is observed at examining the irradiated healthy donors blood, which testifies to nonrandomness of such results. For the radiobiological interpretation of such character of dose curves, the study of dose dependence on chromosomes aberrations frequency is required with use of a cytogenetic biodosimeter. Earlier we established (Domina E., 2016) that irradiation of lymphocytes culture in wide range of doses resulted in obtaining abnormal dose curves with dose-independent site (plateau) in the small doses range for the general frequency of chromosomes aberrations and X-ray markers. Conclusion. The data obtained at the biochemical level of blood lymphocytes of cancer patients indicate a violation of oxidative metabolism even when irradiated in small doses. Violation of oxidative metabolism can be received by healthy cells from the tumor environment. 


\title{
Biological features of ethylthiosulfanylate influence on the activity of antioxidant enzymes in rat kidneys under the action of $\mathrm{Cr}(\mathrm{VI})$
}

\author{
B. I. Kotyk ${ }^{1}$, R. Ya. Iskra1, O. Z. Svarchevska² \\ ${ }^{1}$ Institute of Animal Biology, NAAS of Ukraine \\ 38, Stusa Str., Lviv, Ukraine, 79034 \\ ${ }^{2}$ Stepan Gzhytskyi National University of Veterinary Medicine and Biotechnologies Lviv \\ 50, Pekarska Str., Lviv, Ukraine, 79010 \\ kicyniabo@gmail.com
}

\begin{abstract}
Aim. Antioxidant system (AOS) maintains at the required level the processes of free radicals and reactive oxygen species formation and attenuates the lipid peroxidation process in the living cells. Cr(VI)-induced oxidative stress leads to disturbance of AOS activity. Ethylthiosulfanylate is a synthetic sulfur-containing organic compound and belongs to the class of thiosulfonates. Thiosulfonates demonstrate antioxidant properties and are involved in the mechanisms of antioxidant enzymes activation. The purpose of the study was to investigate the influence of ethylthiosulfanylate on the superoxide dismutase (SOD) and catalase (CAT) activity in kidneys of rats exposed to $\mathrm{Cr}(\mathrm{VI})$. Methods. White male Wistar laboratory rats were divided into 7 groups. Animals of Group I were intraperitoneally injected with $150 \mu \mathrm{l}$ of physiological solution daily for 14 days. Rats of group II received intragastric injection of $1 \mathrm{ml}$ of oil daily for 14 days. Animals of groups III, IV, VI and VII were intraperitoneally administered daily with $\mathrm{K}_{2} \mathrm{Cr}_{2} \mathrm{O}_{7}$ in a dose of $2.5 \mathrm{mg} \mathrm{Cr}$ (VI) / $\mathrm{kg}$ body weight, for 7 (III, VI group) and 14 days (groups IV and VII). Rats of groups V, VI and VII were intragastrically injected with ethylthiosulfanylate oily solution at a rate of $100 \mathrm{mg} / \mathrm{kg}$ of body weight daily for 14 days. In rat liver homogenates the SOD and CAT activity was determined. All calculations were performed mathematically and statistically using Microsoft Excel software. Results. The SOD and CAT activity increased in rat kidneys of group III compared to the group I by 73 and $32 \%$, respectively. However, SOD and CAT activity decreased in kidneys of rats of group IV relative to the group I by 24 and $22 \%$, respectively. The activity of SOD increased by $20 \%$ in kidney tissue of animals of group V in comparison with group II. SOD activated also by $60 \%$ stronger in rat kidney tissue of group VI relative to the group II. SOD activity was lower by $6 \%$ in kidneys of animals of group VII compared with group II. However, the decrease of SOD activity in the rat kidneys of groups VII $(6 \%)$ relative to the group II was by $18 \%$ lower than the percentage decrease of SOD activity in the kidneys of animals of groups IV ( $24 \%$ ) compared to the group I. Conclusions. Therefore, the $\mathrm{Cr}(\mathrm{VI})$-induced oxidative stress leads to the compensatory activation of SOD and CAT enzymatic activity after 7 days of potassium dichromate administration (group III). The $\mathrm{Cr}(\mathrm{VI})$ action during 14 days (group IV) causes depletion of these enzymes activity in the kidneys of animals. The intragastric administration of ethylthiosulfanylate stimulates SOD activity (groups V and VI) and prevents depletion of SOD activity in rat kidneys under the condition of $\mathrm{K}_{2} \mathrm{Cr}_{2} \mathrm{O}_{7}$-induced oxidative stress (group VII).
\end{abstract}




\title{
Expression of long non-coding RNAs HIF1A-AS1, LIPCAR, and MIAT under remote ischemic preconditioning in patients with coronary artery disease
}

\author{
M. Khetsuriani ${ }^{1}$, N. O. Ioffe ${ }^{2}$, T. I. Drevytska ${ }^{1}$, V. N. Niekrasova ${ }^{3}$, V. E. Dosenko ${ }^{1}$ \\ ${ }^{1}$ O. O. Bogomoletz Institute of Physiology, NAS of Ukraine \\ 4, Akademika Bogomoltsa Str., Kyiv, Ukraine, 01004 \\ 2 Amosov National Institute of Cardiovascular Surgery \\ 6, Amosov Str., Kyiv, Ukraine, 03038 \\ ${ }^{3}$ Educational and Scientific Center "Institute of Biology and Medicine", \\ Taras Shevchenko National University of Kyiv \\ 64/13, Volodymyrska Str., Kyiv, Ukraine, 01601 \\ michael.khetsuriani@gmail.com
}

\begin{abstract}
Aim. Long non-coding RNAs (lncRNAs) is a wide class of molecules that represent a significant part of the transcript and perform numerous regulatory functions at transcriptional and posttranscriptional levels. Recent studies have shown that lncRNAs are involved in the regulation of various intracellular processes in the development of numerous cardiovascular diseases. Main objective of this research was to estimate the expression level of lncRNAs HIF1AAS1, LIPCAR and MIAT under the influence of remote ischemic preconditioning (RIPC) in patients with coronary artery disease who are indicated for surgical intervention. Methods. To conduct this study two groups of patients were selected. Before the surgery one group (8 patients) underwent RIPC using a blood-pressure cuff, and the second group (7 patients) underwent the sham procedure (without inflation in the cuff). Blood samples were taken from both groups of patients before and after RIPC. Additionally, the myocardial biopsy samples were taken during the surgery. The expression analysis of lncRNAs in blood plasma, leukocyte fraction and heart tissue was carried out by real-time PCR using specific primers. Results. Our studies have shown that the expression level of lncRNAs HIF1A-AS1, MIAT and LIPCAR significantly decreased in myocardium and plasma in RIPC group compared with the sham group. In the myocardium, the MIAT level decreased by almost 7 times, the HIF1A-AS1 level decreased by 4 times, and the LIPCAR level by almost 10 times. The plasma level of HIF1A-AS1 decreased by almost 10 times in RIPC group compared with the sham group. The expression level of LIPCAR and MIAT decreased by 26 and 2 times respectively. Interestingly, the opposite situation is observed in leukocytes. In RIPC group the expression level of lncRNAs HIF1A-AS1, LIPCAR and MIAT significantly increased - by 5, 4 and 9 times respectively. We also determined the level of HIF-1 $\alpha$ expression. In the RIPC group, the level of $H I F-1 \alpha$ decreased in both myocardium and leukocytes, which probably indicates its regulation by HIF1A-AS1. Conclusion. Our studies suggest that the lncRNA HIF1A-AS1, which is a natural antisense for $H I F-1 \alpha$ mRNA, can be involved in the regulation of $H I F-1 \alpha$ expression in myocardium and leukocytes. As for IncRNAs LIPCAR and MIAT a significant decrease in their expression in heart tissues and plasma in the patients with RIPC demonstrates the protective effect of RIPC on the heart.
\end{abstract}




\title{
Multiple sequential administration of vitamin $A$ in the formation of resistance to the toxic effect of copper ions
}

\author{
A. V. Novikova, R. A. Akzhyhitov \\ V. N. Karazin Kharkiv National University \\ 4, Svobody Ave., Kharkiv, Ukraine, 61077 \\ nav_kh@ukr.net
}

Introduction. The formation of mechanisms of resistance to toxic compounds, drugs, physical influences is one of the central problems of physiology: on the one hand, it ensures the survival of the organism in extreme conditions, and on the other hand, it prevents the elimination of a number of pathologies. Consequently, knowledge of the molecular mechanisms of adaptation is of great theoretical and practical importance. In this regard, the aim of the work was to investigate the effect of vitamin A as an antioxidant on the formation of resistance to repeated injections of copper ions (intoxication). Methods. The experiment was carried out on three-month-old male Wistar rats. To induce fibrotic changes in the liver, intraperitoneal injections of a solution of copper sulfate at a concentration of $1 \mathrm{mg} \mathrm{Cu}^{+} / 100 \mathrm{~g}$ of body weight were performed three times every 48 hours. Then, to study the effect of vitamin $\mathrm{A}$ in the formation of resistance to intoxication, parts of the animals were injected per os with an oil solution of vitamin A at the rate of $300 \mathrm{IU} / 100 \mathrm{~g}$ of body weight with an interval of 24 hours for 4, 7, 14 and 21 days for different experimental groups. The content of vitamins A, E, C, as well as a number of biochemical indicators of the functional state of the liver of animals were investigated. Results. Earlier in our laboratory it was shown that repeated administration of copper sulfate to animals leads to the formation of liver fibrosis (Bozhkov A.I., etc., 2017). Therefore, it was of interest to investigate the effect of vitamin A on these processes. It was noted that hypervitaminosis caused by daily vitamin A administration was accompanied by growth retardation and weight loss, regardless of the presence or absence of $\mathrm{Cu}$-induced liver fibrosis. In the course of the work, it was revealed that against the background of daily injections of vitamin A, there was a U-shaped character of changes in the content of vitamin A in the liver. It was also shown that an increase of vitamin $\mathrm{A}$ in the liver was accompanied by a decrease of vitamins $\mathrm{E}$ and $\mathrm{C}$. After 7 days of the experiment, significant differences between the group with induced liver fibrosis and the group with induced fibrosis and hypervitaminosis A were not observed in most of the studied parameters (ALT and GGT activity, concentration of creatinine, urea and cholesterol). However, differences were observed in the activity of alkaline phosphatase: it decreased in rats with liver fibrosis by $53 \%$ compared to intact animals, and the introduction of vitamin A against the background of fibrotic changes in the liver led to the normalization of this indicator. Conclusion. The introduction of vitamin A to animals influenced the formation of resistance to toxicants. 


\title{
Effect of artificially introduced magnetic nanoparticles on animal metabolism
}

\author{
M. O. Bulaievska, S. V. Gorobets, O. Yu. Gorobets \\ National Technical University of Ukraine "Igor Sikorsky Kyiv Polytechnic Institute" \\ 37, Pobedy Av., Kyiv, Ukraine, 03056 \\ bulaievska.mo@ukr.net
}

\begin{abstract}
Aim. Due to the unique properties, magnetic nanoparticles have a high potential in such biomedical fields as [1]: modification and separation of cells, as a tool for researching cell biology, including the isolation and purification of cell populations; restoration of biological tissues; targeted drug delivery; magnetic resonance imaging; hyperthermia, etc. Magnetic nanoparticles, in particular iron oxide nanoparticles, are widely used for biomedical purposes in vivo [2]. Analysis of the magnetic and toxicological properties shows that nanoparticles based on iron oxides, along with rather effective magnetic characteristics, are significantly less toxic than their analogs [3]. However, all pharmaceutical substances intended for the use in humans and animals require careful research. Methods. In this work, the effect of artificial magnetic nanoparticles on the metabolism of Danio rerio fish was investigated. Experimental animals (10 individuals) were orally injected with $100 \mu \mathrm{l}$ of magnetic fluid with a concentration of magnetic nanoparticles of $0.02 \mathrm{mg} / \mathrm{g}$. Control animals (10 individuals) were injected with $100 \mu \mathrm{l}$ of distilled water. Danio rerio adults were used in the 5-6 month age group. A solution of magnetite $\left(\mathrm{Fe}_{3} \mathrm{O}_{4}\right)$ was injected daily for 28 days. Results. As a result of the study, it was shown that the average weight of the animals in the experimental group is $9 \%$ higher than that of the animals in control group, which indicates the effect of a magnetite solution at a concentration of $0.02 \mathrm{mg} / \mathrm{g}$ on the metabolism of Danio rerio fish. Conclusions. The obtained results of the effect of artificial magnetic nanoparticles on the metabolism of animals are fully consistent with the results obtained in similar studies on plants, fungi [4] and bacteria [5].
\end{abstract}

1. Pankhurst Q.A., Connolly J., Jones S.K., Dobson J. Applications of magnetic nanoparticles in biomedicine. J Phys D: Appl Phys. 2003; 36: 167-181.

2. Levy M., Lagarde F., Maraloiu V.-A., Blanchin M.-G., Gendron F., Wilhelm C., Gazeau F. Degradability of superparamagnetic nanoparticles in a model of intracellular environment: follow-up of magnetic, structural and chemical properties. Nanotechnology. 2010; 21: 395103

3. Kaminski M.D., Rosengart A.J. Detoxification of blood using injectable magnetic nanoparticles: a conceptual technology description. J. Magn. Magn. Mater. 2005; 293: 389.

4. Gorobets O. Yu., Gorobets S. V., Gorobets Yu. I. Biogenic Magnetic Nanoparticles In Metabolism From Bacteria To Human. ISBN 978-3-330-00964-6, LAP LAMBERT Academic Publishing. 2020; 164 p.

5. Gorobets S.V., Gorobets O.Yu., Sharau I.V., Milenko Yu.V. Magnetically controlled vector based on E. coli Nissle 1917, 2020 https://arxiv.org/abs/2002.01958 


\title{
The metabolic profile of circulating phagocytes in animals with different models of Parkinson's disease
}

\author{
Z. I. Oliynyk, V. M. Svyatetska, A. S. Marunchenko, T. V. Dovbynchuk, G. M. Tolstanova \\ Educational and Scientific Center "Institute of Biology and Medicine", \\ Taras Shevchenko National University of Kyiv \\ 64/13, Volodymyrska Str., Kyiv, Ukraine, 01601 \\ ojankin@yahoo.com
}

Introduction. Parkinson's disease (PD) is a common neurodegenerative disease characterized by the loss of dopaminergic neurons. The molecular basis for the development of PD has not been determined yet. The accumulated data on animal models indicate the involvement of inflammation in the progression of the disease, where local neuroinflammation gradually increases with the development of systemic inflammatory process. The reproduction of systemic inflammation is an important component of PD modeling. One of the key markers of systemic inflammation is quantitative and functional characteristics of circulating innate immunity cells: neutrophils $(\mathrm{N})$ and monocytes $(\mathrm{Mo})$. The aim of the study was to compare the metabolic profile of circulating phagocytes in rats 6-OHDA - and LPS-induced PD. Methods. PD was induced by stereotactic administration of LPS and 6-OHDA to Wistar rats. The dopaminergic neuron loss was evaluated in the apomorphine test and by immunohistochemical examination of tyrosine hydroxylase. Studies of the metabolic profile of circulating phagocytes were performed at the end of the experiment. To assess the metabolic profile of Mo and N, the phagocytic activity, oxidative metabolism, and CD206 expression were studied by flow cytometry. The intact and sham-operated animals were used as a control. Results. The phagocytic activity of circulating phagocytes in rats with 6-OHDA-PD did not differ significantly as compared to control animals. The Oxidative metabolism of Mo and $\mathrm{N}$ in rats with this model of the disease was significantly (by $\sim 3$ times) reduced compared with intact and shamoperated animals at the end of the experiment. The expression of CD206 - the mannose receptor, which is a marker of anti-inflammatory metabolic activation of myeloid cells - was increased in a population of circulating phagocytes. These data may indicate the absence of pronounced pro-inflammatory activation of circulating cells, which can be explained by both spontaneous resolution of the systemic inflammatory process and phagocyte metabolic exhaustion. In animals with LPS-PD, the phagocytic activity, as well as the CD206 expression did not differ substantially from the values of control animals. The indicators of oxidative metabolism of Mo and $\mathrm{N}$ in the blood of animals with LPS-PD significantly exceeded those in the control groups. This indicates the pro-inflammatory metabolic shift in cells and can be considered as a marker of systemic inflammation. Conclusion. The metabolic profiles in rats with 6-OHDA-PD and LPS-PD differ from one another. The reproduction of systemic inflammation inherent for the clinical course of PD, which was characterized in this study by a proinflammatory metabolic shift of circulating Mo and N, was observed only in animals with LRS-PD. This indicates a greater adequacy of the LPS-induced model of PD for the study of inflammatory component of the disease pathophysiology. 


\title{
Adolescent social isolation alters synaptic plasticity along the hippocampal dorsoventral axis
}

\author{
O. M. Nikolaienko ${ }^{1}$, M. O. Semenikhina ${ }^{1}$, M. Y. Klymenkoํㅐ A. V. Savotchenko ${ }^{1}$, \\ E. V. Isaeva ${ }^{2}$ \\ ${ }^{1}$ O. O. Bogomoletz Institute of Physiology, NAS of Ukraine \\ 4, Akademika Bogomoltsa Str., Kyiv, Ukraine, 01004 \\ ${ }^{2}$ Medical College of Wisconsin, \\ Milwaukee, Wisconsin \\ oksana.nikolaienko@gmail.com
}

Introduction. Social isolation has become an important public health issue since the COVID-19 pandemic outbreak. Lack of social contacts is especially challenging for adolescents because social interaction at this age is essential for healthy neuroendocrine system maturation. Aim. This study aimed to investigate the effect of adolescent social isolation on synaptic plasticity in the dorsal and ventral hippocampus of rats. Methods. Male Wistar rats were randomly assigned into either isolation-housing or group-housing immediately after weaning at postnatal day 23-25. After 4 weeks of different housing conditions, acute hippocampal slices ( $400 \mu \mathrm{m}$ thick) were prepared from dorsal $(\mathrm{DH})$ and ventral $(\mathrm{VH})$ poles of the hippocampus. Field excitatory postsynaptic potentials (fEPSP) were recorded from the stratum radiatum of the hippocampal CA1 region after stimulation of the Schaffer collateral. Long-term potentiation (LTP) was elicited by a high-frequency tetanic stimulation (HFS) train (100 Hz, $1 \mathrm{~s})$, after which changes in the fEPSP were recorded. The period between 1 and 10 minutes after HFS was defined as short-term potentiation (STP). LTP was evaluated by averaging synaptic responses from 30 to 40 minutes after HFS. Results. We found that socially isolated rats had increased STP in the VH $(166.4 \pm 7.3 \%$ vs. $137.1 \pm 5.0 \%$ in group-housed rats, $\mathrm{p}<0.05)$, while no changes were observed in the DH $(165.3 \pm 4.9 \%$ vs. $162.3 \pm 4.1 \%$ in group-housed rats). Moreover, group-housed rats showed significant dorsoventral differences in STP $(p<0.05)$, while fEPSP slopes in the DH and VH of isolated rats were similar. We also found that this dorsoventral heterogeneity was maintained in LTP of the group-housed rats (group-housed DH: $142.2 \pm 8.3 \%$ vs. group-housed VH: $110.9 \pm 4.6 \%, \mathrm{P}<0.05$ ), while there was no difference between $\mathrm{DH}$ and $\mathrm{VH}$ in the isolated group (isolated $\mathrm{DH}$ : $134.6 \pm 8.9 \%$ vs. isolated VH: $122.0 \pm 5.6 \%$ ). Conclusions. Our results indicate that prolonged adolescent social isolation enhances short-term potentiation in the ventral hippocampus and abolishes dorsoventral heterogeneity in short-term and long-term potentiation. These alterations in hippocampal synaptic plasticity may have a role in the cognitive and behavioral disorders induced by social isolation. 


\title{
Accumulation of administrated artificial magnetic nanoparticles in animal organs on the example of Danio rerio
}

\author{
Yu. V. Lebedynska, S. V. Gorobets, M. O. Bulaievska \\ National Technical University of Ukraine "Igor Sikorsky Kyiv Polytechnic Institute" \\ 37, Pobedy Av., Kyiv, Ukraine, 03056 \\ yu.lebedynska@gmail.com
}

Introduction. The ability to synthesize biogenic magnetic nanoparticles (BMN) has been proven for representatives of prokaryotes, archaea and eukaryotes, including animals [1]. Administrated artificial magnetic nanoparticles (NPs) in animals accumulate in the brain, heart, liver, kidneys and lungs [2], in the organs, in which the presence of BMN has been established. Aim. Study of artificial magnetic labeling and natural magnetic labeling of animal cells on the example of Danio rerio. Methods. Bioinformation methods (methods of comparative genomics); biological (dissection of organs); physicochemical methods (light microscopy, Perls reaction). Results. According to the results of BLAST-search of homologues of MTB proteins (MamA, MamB, MamM, MamE, MamO, MamK) in the Danio rerio proteome, it is possible to establish the potential possibility of Danio rerio to synthesize intracellular crystalline BMNs, because in its proteome there are homologues of the most important proteins. The accumulation of artificial magnetic nanoparticles in brain, heart, liver and kidneys of Danio rerio was studied. We used adult males Danio rerio weighing from 0.5 to $0.8 \mathrm{~g}$. Experimental animals (10 individuals) were orally administered with $100 \mu$ of magnetic fluid with a concentration of magnetic nanoparticles $0.02 \mathrm{mg} / \mathrm{g}$. Control animals were injected with $100 \mu \mathrm{l}$ of distilled water. The presence of iron in the form of oxidative compounds, according to the Perls reaction, was investigated in the organs of fish after administration of nanoparticles of magnetite $\mathrm{Fe}_{3} \mathrm{O}_{4}$ during 24 hours, 7 days, 14 days, 28 days and 56 days. In the studied organs, brain, heart, liver and kidneys, the structural elements were found that give a positive Perls reaction, which indicates the presence of iron oxidizing compounds in both experimental and control samples. Moreover, a significantly smaller number of such structural elements were detected in the control samples, which indicates a smaller number of oxidizing compounds of iron. Conclusions. It can be concluded that in the control samples, the positive reaction of Perls is caused by the presence of BMNs in the studied organs of Danio rerio. The accumulation of artificial magnetic nanoparticles in the organs of the experimental group of animals can be associated with the presence of BMNs in the studied organs.

1. Gorobets S.V. et al. Biomineralization of biogenic magnetic nanoparticles and their possible functions in cells of prokaryotes and eukaryotes. Dekker Encyclopedia of Nanoscience and Nanotechnology. 3rd ed. 2014; 300-6.

2. Kim J.S. et al. Toxicity and Tissue Distribution of Magnetic Nanoparticles in Mice. 2005; 89(1): 338-447. 


\title{
Impact of anticancer drugs synergy on breast cancer cell models: 2D and 3D
}

\author{
Y. M. Khmelnytska ${ }^{1,2}$, O. M. Perepelytsina ${ }^{1}$, M. Sydorenko ${ }^{1}$ \\ ${ }^{1}$ Institute for Problems of Cryobiology and Cryomedicine, NAS of Ukraine \\ 23, Pereyaslavskaya Str., Kharkiv, Ukraine, 61015 \\ 2 Educational and Scientific Center "Institute of Biology and Medicine", \\ Taras Shevchenko National University of Kyiv \\ 64/13, Volodymyrska Str., Kyiv, Ukraine, 01601 \\ iuliakhmelnitska@gmail.com
}

Background. Tumors consist of different types of cancer cells such as ordinary tumor cells and cancer stem cells. It is important to find targeting anticancer therapeutic agents for the heterogeneous tumor cell population. Methods. The MCF-7 cells were cultured in standard conditions in 2D and 3D cultures. MCF-7 spheroids were generated in $2 \%$ carboxymethyl cellulose (Sigma, USA) and incubated on an orbital shaker (PSU-10i, Biosan, Latvia) at $80 \mathrm{rpm}$ for 3-5 hours under the non-adhesive conditions. The combinations of antitumor drugs were added in the following concentrations: Salinomycin 4 and $40 \mu \mathrm{M}+$ Cisplatin 0.01 and $0.1 \mu \mathrm{g} \mathrm{ml}$; Salinomycin 4 and $40 \mu \mathrm{M}+$ Doxorubicin 0.1 and $1 \mu \mathrm{g} / \mathrm{ml}$. Cytotoxicity of antitumor drugs was analyzed in 2D model by MTT-test. On 3D model, morphometric assay was performed on Zeiss Stemy 2000 by AxioVision (Zeiss) software. Cancer stem cell (CSC) markers (bmi-1, CD44, CD133) and cytokeratin (AE1/AE3) were detected by immunochemistry in 2D cell culture. Results. It was demonstrated that the IC50 for Sal+Dox $0.1 \mu \mathrm{g} / \mathrm{ml}-22.9 \mu \mathrm{g} / \mathrm{ml}$, IC50 for Sal+Dox $1 \mu \mathrm{g} / \mathrm{ml}-20.9 \mu \mathrm{g} / \mathrm{ml}$, IC50 for Sal+Cispl 0.01-23.3 $\mu \mathrm{g} / \mathrm{ml}$. So, Sal and Cispl $0.1 \mu \mathrm{g} / \mathrm{ml}$ had the greatest cytotoxic effects on cells $-13.3 \mu \mathrm{g} / \mathrm{ml}$. Cytotoxicity of antitumor drugs on tumor spheroids with Sal $40 \mu \mathrm{M}+$ Dox $1 \mu \mathrm{g} / \mathrm{ml}$ and Sal $40 \mu \mathrm{M}+$ Cispl $0.1 \mu \mathrm{g} / \mathrm{ml}$ was reflected in decreasing spheroid volume by $99 \%$ and $98 \%$, respectively. The decreasing of spheroids size was dose-dependent from $4 \mu \mathrm{M}$ to $40 \mu \mathrm{M}$ of Salinomycin. The percentage of CSC markers (bmi-1, CD44, CD133) in 2D culture was 3-4.5 times lower after incubation with Sal $40 \mu \mathrm{M}+\mathrm{Cispl} 0.01-0.1 \mu \mathrm{g} / \mathrm{ml}$ than in control samples. The expression of cytokeratin marker increased by $280 \%$ compared to control after incubation with Sal $40 \mu \mathrm{M}+\mathrm{Cispl} 0.01-0.1 \mu \mathrm{g} / \mathrm{ml}$. The CSC markers expression remained at the same level as the control or slightly increased after cell incubation with Sal $40 \mu \mathrm{M}+$ Dox $0.1-1 \mu \mathrm{g} / \mathrm{ml}$.

Conclusion. Our results demonstrated that incubation of 2D and 3D models of MCF-7 cells with combinations of Sal + Cispl and Sal + Dox led to the decline of tumor cell viability, reduction of the average volume of spheroids and decrease of CSC population. These data showed that Sal has a cytotoxic influence on CSC population and synergic activity with Dox and Cispl. 


\title{
Lipase like a strategically important enzyme in the industry
}

\author{
T. S. Gunko, T. V. Ivanova \\ National University of Life and Environmental Sciences of Ukraine \\ 15, Heroiv Oborony St., Kyiv, Ukraine,03041 \\ tania.gunko.95@gmail.com
}

Introduction. Lipases are very versatile enzymes employed in several industries. They catalyze the hydrolysis, etherification and alcoholysis reactions. Lipase can be obtained from different sources including animal, plant and microbial organisms. The production of lipases of microbial origin develops very quickly and has a wide use in different industries. The aim of our research was the identification of priority areas for the use of lipases in industry. Results. Today, the most promising source of lipases is a wide range of microorganisms of different taxonomic groups. In particular, the bacteria and fungi permit manipulating the growth of the target product. The advantage of microbiological synthesis of lipolithic enzymes is primarily high growth rates. Moreover, it is a powerful enzyme apparatus possessing a possibility of genetic manipulations with microorganisms. Active producers of lipases were found among bacteria of the genera Pseudomonas, Bacillus, Acinetobacter, Propionibacterium, Chromobacterium, Serratia, Geobacilli; actinomycetes Streptomyces flavogriseus, Thermoactinomyces vulgaris; yeast cultures of the genera Candida (Candida lipolytica, Candida paralipolytica, Candida cylindraceae), Rhodotorula, Saccharomyces, Torulospora, Trichosporon. Lipase is a multifunctional biological catalyst that provides requirements for the production of biodiesel, food and beverages, leather, etc. First of all, lipase has been used by the food industry in the production of cheese, bread, cereal. Today, the practical use of lipase is the manufacture of milk chocolate, hydrolysis of residual fat in dried egg protein, beverage preparation and production of vegetable oils. Moreover, it is used in the light industry for the manufacture of fur and leather, silk processing and detergent production. The use of lipase has a positive effect on the treatment of the human pancreas. In addition to therapeutic purposes, it is applied as an additive to cosmetics. This enzyme is important for environmental problems, such as wastewater treatment and sanitation, as well as waste disposal in the oil industry. The good examples of the usages of lipases in agriculture are the preparation of easily digestible feeds and the improvement of metabolism in animals. Conclusion. The use of lipases in food industry is beneficial from both economic and environmental points of view. The demand for the use of this enzyme is constantly expanding and finds new ways of application. 


\title{
The influence of rocuronium and pipecuronium bromides on the large conductance cation channels in nuclear membrane of cerebral Purkinje neurones
}

\author{
O. V. Tarnopolska, O. A. Kotyk, A. B. Kotliarova, S. M. Marchenko \\ O. O. Bogomoletz Institute of Physiology, NAS of Ukraine \\ 4, Akademika Bogomoltsa Str., Kyiv, Ukraine, 01004 \\ tarnopolskaolga@gmail.com
}

Introduction. The nuclear envelope isolates nucleoplasm from the cytoplasm, it consists of two membranes and perinuclear space. Nuclear transport between cytoplasm and nucleoplasm is provided mainly by nuclear pores, which penetrate through both membranes. But beyond that, there are a lot of different ion channels at external and internal nuclear membranes, which makes possible the transport between nuclear lamina and nucleoplasm/cytoplasm. LCC-channels (Large-Conductance Cationic channels) were first detected in the nuclear membranes of cerebellar Purkinje neurons by patch-clamp technique (Marchenko, 2005). These channels are potential-dependent, selective to small monovalent cations and impermeable to divalent cations. Currently we are looking for effective and specific LCC-channels blockers. Their identification is the first step for ascertaining the physiological role of the channels. Aim. The goal of this work was to investigate the effect of N-choline receptor inhibitors - rocuronium and pipecuronium bromides - on the LCC-channels in the inner nuclear membrane of cerebellar Purkinje neurones. Methods. The research was performed on 3-4 weeks-old Wistar and Fisher rats. The nuclei from cerebellar Purkinje neurons were isolated by homogenization and subsequent centrifugation of received suspensions. The technique of nuclei isolation from cerebellar Purkinje neurons is described in detail in (Marchenko 2005). Currents through individual ion channels were registered in the "nucleus-attached" or "excised patch" configuration of the patch-clamp technique. The obtained results were analyzed using Clampfit 10.3. and OriginPro 9.0. Results. Bromides of pipecuronium and rocuronium have a pronounced inhibitory effect on the LCC-channels of the nuclear membranes of the Purkinje cerebellar neurons. Pipecuronium bromide at concentration $2 \mathrm{mM}$ reduces average current through the LCC-channels by $68 \%$, whereas Rocuronium bromide at the same concentration reduces the current by $52 \%$. In the next series of experiments we investigated the dependence of the effect of the substances mentioned above on the potential applied. We have found that blocking is more effective at the negative potential values. Both pipecuronium and rocuronium bromides cause channels «flickering», the degree of which depends on the concentration of the active substance. No significant changes were registered in the average duration of the channel being in the open state under the influence of these substances. Conclusions. Using patch-clamp technique we confirmed that rocuronium and pipecuronium bromides decrease the current through the LCC-channels of nuclear membrane of cerebellar Purkinje neurons in dose-dependent manner. The effectiveness of such blocking is higher at the negative potential values. 


\title{
In vitro evaluation of bull semen processed with copper nanoparticles
}

\author{
O. Yu. Slyvchuk \\ Institute of Animal Biology, NAAS of Ukraine \\ 38, Stusa Str., Lviv, Ukraine, 79034 \\ free.code.online@gmail.com
}

Introduction. Copper is an important trace element that is required to the proper functioning of some metabolic processes. It is essential for the male reproductive system and its deficiency leads to impaired spermatogenesis. However, little is known about the effect of copper in the regulation of forward progression of mammalian sperm cells. Aim. The current study investigated the effect of copper nanoparticles (CuNPs) on bull semen quality and various biochemical components of seminal plasma. Methods. The semen quality and biochemical findings non-treated control and experimental groups treated with $0.1,1$ and $2 \mu \mathrm{l} / \mathrm{ml} \mathrm{CuNPs}$ were compared following 5, 18, 48 and $96 \mathrm{~h}$ intervals. We estimated the values of some biochemical components, viz., total protein content, and enzymes such as alkaline phosphatase (ALP), aspartate aminotransferase (AST), and lactate dehydrogenase (LDH) as well as concentrations of total calcium $(\mathrm{Ca})$, phosphorus $(\mathrm{P})$, magnesium $(\mathrm{Mg})$, sodium $(\mathrm{Na})$, potassium $(\mathrm{K})$. Results. There were no negative effects in the percentage of motility, live spermatozoa and total morphological defects in experimental groups during 18 hours of storage at $4{ }^{\circ} \mathrm{C}$. The semen quality in the first group treated with $0.1 \mu \mathrm{l} \mathrm{CuNPs}$ for all intervals was significantly higher as compared with the control group $(\mathrm{P}<0.05-\mathrm{P}<0.01)$. The spermatozoal survivability in other experimental groups was at the level of the control group. The activity of AST and LDH was significantly increased in the dynamics during the long-term storage in all groups, however the activity of these enzymes, as compared with control values, was lower in groups with $1 \mu \mathrm{l}$ and $2 \mu \mathrm{l} \mathrm{CuNPs}$. ALP activity in the first group with lower CuNPs concentration was significantly higher $(\mathrm{P}<0.05)$ during 18 hours of storage of the diluted semen at $4{ }^{\circ} \mathrm{C}$, whereas in the experimental groups treated with higher levels of CuNPs $(1 \mu \mathrm{g}$ and $2 \mu \mathrm{g})$ the enzyme activity was significantly lower, as compared with the control group at 18 and 96 hour $(\mathrm{P}<0.001)$. This study showed that the seminal plasma calcium level significantly decreased in the groups with higher CuNPs concentration compared to control $(\mathrm{P}<0.05$ 0.01 ), whereas the mean $\mathrm{P}$ and $\mathrm{K}$ concentrations did not differ significantly between groups. Conclusion. Supplementation of $\mathrm{Cu}$ nanoparticles to semen has improved its quality, as confirmed by the obtained biochemical parameters. 


\title{
Development of experimental model of ARDS in SHR strain old rats
}

\author{
A.V. Savotchenko, Y. M. Tkachenko, T. I. Drevytska, R. O. Morhachov, S. O. Demchenko, \\ M. V. Stefanenko, D. S. Isaev \\ O. O. Bogomoletz Institute of Physiology, NAS of Ukraine \\ 4, Akademika Bogomoltsa Str., Kyiv, Ukraine, 01004 \\ savrasova10@gmail.com
}

Introduction. ARDS (acute respiratory distress syndrome) is a direct cause of death due to lung lesions of various origins including SARS-CoV-2 infection. Most lung and respiratory diseases are characterized by inflammation, which in turn causes occlusions, mucous hypersecretion, shortness of breath, cough and other symptoms of airway inflammation. Understanding the pathological processes involved in the regulation of the immune response may lead to the discovery of new mechanisms that support or suppress inflammatory processes in the lungs and respiratory tract. Methods. In order to develop the experimental model of ARDS we used precision pulmonary hyperventilation and intratracheal administration of poly I:C, which reproduces the body's response to viral infection (mimic viral infection). The severity of ARDS was estimated by the following parameters: the ratio of wet lung weight to dry lung (wet/dry lung weight), extensibility, impedance, lung stiffness, protein level and the number of neutrophils in the bronchial lavage, the level of proinflammatory cytokines in lung tissue. Moreover, we provide a method of simultaneous registration of the lungs vagal nerve activation parameters due to ARDS induction. It is known that the lungs have a massive innervation of the peripheral nervous system and such innervation has a powerful effect on the cells of the immune system. Results. The biologically active substances of neurons affect the activity of immune cells, and the activity of the immune system affects the functioning of the nervous system. That is why the investigation of neuro-immune interaction has a great potential in studying ARDS. Evaluation of dynamic changes in respiratory function due to simulated ARDS showed a significant increase in such parameters as Newtonian resistance, tissue stiffness, static elongation, and a decrease in elasticity and tissue dumping, which is fully consistent with the pathogenesis of ARDS in patients. Analysis of the dry/wet lung ratio showed a two-fold increase in pulmonary edema, a severe, life-threatening condition that develops as a result of ARDS. Significant increase of the protein content and concentration of neutrophils in bronchopulmonary lavage indicates an increase in the permeability of the pulmonary capillaries due to ARDS. The real time PCR identified significant increase of proinflammatory chemokine Cxl2 concentration. Also we observed an increase of neutrophil-activating protein 3 cytokine Gro1, which stimulates the migration of neutrophils. Electrophysiological registration of the activity of the vagal nerve innervating the lungs showed a significant increase in the activity of nociceptive and mechanosensitive fibers, especially in the last stage of acute respiratory distress syndrome, which confirms the role of the nervous system in this pathology. Conclusion. As a result we obtained a model that reproduces ARDS most relevant to human pathological condition. 


\title{
A new nanocomposite amperometric biosensor for L-lactate determination
}

\author{
A. A. Vorobiienko, O. A. Biloivan \\ Institute of Molecular Biology and Genetics, NAS of Ukraine \\ 150, Akademika Zabolotnoho Str., Kyiv, Ukraine, 03143 \\ o.a.biloivan@edu.imbg.org.ua \\ biology20@ukr.net
}

\begin{abstract}
Aim. The development of nanocomposite biosensor based on printed carbon electrode and immobilized lactate dehydrogenase for 1-lactate determination in sweat. Methods. Electrochemical analysis of L-lactate provided by detecting reduced nicotinamide adenine dinucleotide (NADH) as a product of enzymatic conversion involving lactate dehydrogenase (LDH). In this regard, the study included the development of a high-performance nanocomposite sensor for monitoring NADH using screen-printed carbon electrodes (SPCEs). Modification of the surface of the working electrode was performed by drop method with a mixture of $\mathrm{N}$-graphene with chitosan. An additional m-phenylenediamine membrane was applied by electropolymerization. The LDH layer was formed by covalent binding to BSA gel in glutaraldehyde vapors. The effects of SPCE modification on their electrochemical properties were investigated by cyclic voltammetry and amperometry. Spectrophotometric methods were used for the enzyme activity control and L-lactate determination in parallel with the biosensor measurements. Results. The laboratory models of an epidermal printed amperometric biosensor were developed for non-invasive determination of lactate in sweat. The analytical characteristics of the biosensors developed were investigated in model solutions (buffer, saline solutions, artificial sweat) in the mode of stationary cell. A comparative analysis of the analytical characteristics of the developed biosensors based on SPEs of different compositions and configurations and immobilized lactate dehydrogenase was performed. The influence of sweat components on the results of L-lactate measurements was studied. The composition of the biosensor and the measurement procedure for the determination of lactate in artificial sweat samples was optimized. The results of L-lactate measurements obtained using the developed laboratory model of sensor system and obtained by the traditional method of analysis are compared. Conclusions. The study has shown that the modification of the surface of the carbon electrode with a layer of $1 \% \mathrm{~N}$-graphene with $1 \%$ chitosan increases the sensitivity three times and reduces the optimal potential for oxidation of NADH on the electrode surface $(0.1-0.3 \mathrm{~V})$. The developed and optimized model of the biosensor based on SPCE C110 (Drop Sens, Spain) and immobilized LDH allows the L-lactate analysis in the range of concentrations of $1-8 \mathrm{mM}$ with a sensitivity of $0.145 \mu \mathrm{A} / \mathrm{mm}$ and detection limit of $50 \mu \mathrm{M}$. It has been shown that an additional polymer membrane based on m-phenylenediamine significantly improves the selectivity of the biosensor. The operational stability of the biosensor was found to be 10 measurements of lactate and stability during storage at $4{ }^{\circ} \mathrm{C}$ in dry form - one month. The fundamental possibility of determining the concentration of lactate in samples of artificial sweat using the developed biosensors is shown.
\end{abstract}




\title{
Expression and purification of cytosolic human alars
}

\author{
O. I. Skydanovych ${ }^{1}$, A. V. Kochutenko², M. Yu. Rybak ${ }^{1}$, M. A. Tukalo ${ }^{1}$ \\ ${ }^{1}$ Institute of Molecular Biology and Genetics, NAS of Ukraine \\ 150, Akademika Zabolotnoho Str., Kyiv, Ukraine, 03143 \\ ${ }^{2}$ Educational and Scientific Center "Institute of Biology and Medicine", \\ Taras Shevchenko National University of Kyiv \\ 64/13, Volodymyrska Str., Kyiv, Ukraine, 01601 \\ sandra.skudanovuch@gmail.com
}

Introduction. Aminoacyl-tRNA synthetases (aaRSs) are the family of enzymes that attach amino acids to cognate tRNAs. Based on the structure of their catalytic domain they were divided into two classes. Alanyl-tRNA synthetase belongs to the class II and is one of the most conservative member of this family. Aim. Expression and purification of cytosolic human AlaRS and obtaining functional protein were a goal of this work. Methods. Plasmid pETDEST42-humanAlaRS kindly provided by Dr. Y-M. Hou (Thomas Jefferson University, USA) was transformed into Rosetta DE3 E. coli cells by electroporation ("Bio-Rad"). The level of protein expression was analyzed in LB medium containing ampicillin $(100 \mu \mathrm{g} / \mathrm{ml})$ and chloramphenicol $(34 \mu \mathrm{g} / \mathrm{ml})$ and monitored by the range of IPTG concentration $(1 \mathrm{mM}, 0.5 \mathrm{mM}$ and $0.1 \mathrm{mM}$ ). Following induction conditions were examined: $+37^{\circ} \mathrm{C} 4$ hours; $+25^{\circ} \mathrm{C} 4$ hours and $+25^{\circ} \mathrm{C}$ overnight. Cells were harvested by centrifugation and the pellet was resuspended in buffer A (20 mM Tris-acetate $\mathrm{pH} 8.0,100 \mathrm{mM} \mathrm{NaCl}, 5 \mathrm{mM} \beta$-ME and $8 \%$ glycerol) including $1 \mathrm{mg} / \mathrm{ml}$ of lysozyme, EDTA-free protease inhibitor cocktail ("Roche") and $200 \mu \mathrm{M}$ PMSF. The cells after incubation were sonicated and centrifugated. The supernatant was mixed with pre-equilibrated Ni-NTA agarose ("Qiagen") and washed by buffer A (with $10 \mathrm{mM}$ imidazole). Protein was eluted by buffer A containing $100 \mathrm{mM}$ imidazole. The preferable fractions were combined, concentrated and purified using HiLoad 16-60 Superdex 200 column ("Pharmacia Biotech"), pre-equilibrated by buffer B (20 mM Tris-acetate $\mathrm{pH} 8.0,200 \mathrm{mM} \mathrm{NaCl}, 5 \mathrm{mM}$ $\beta$-ME). After each purification the obtained fractions were analyzed by $10 \%$ SDS-PAGE and Bradford microassay. The activity of concentrated protein was tested by aminoacylation assay performed at $+37{ }^{\circ} \mathrm{C}$ during $10 \mathrm{~min}$ in reaction mixture $(75 \mathrm{mM}$ HEPES-NaOH $(\mathrm{pH} 7.5$ at RT), $10 \mathrm{mM} \mathrm{MgCl}, 20 \mathrm{mM} \mathrm{KCl}, 1 \mathrm{mM}$ DTT, $100 \mu \mathrm{g} / \mathrm{ml}$ BSA, $0.5 \mathrm{u} / \mathrm{ml}$ iPPase, $4 \mathrm{mM}$ ATP, $10 \mu \mathrm{M}$ Thermus thermophilus tRNAAla, $25 \mu \mathrm{M}$ [14C]-L-Ala (158 mCi/mmol, "Amersham"), AlaRS $(20 \mathrm{nM}-1 \mu \mathrm{M}))$. Results. Optimal protein expression conditions are the following: overnight growth at $+25{ }^{\circ} \mathrm{C}$ after $1 \mathrm{mM}$ IPTG induction. The amount of purified protein isolated from $1 \mathrm{~L}$ of media was $3.38 \mathrm{mg}$. The initial levels of aminoacylation by AlaRS were detected, activity of enzyme was confirmed. Conclusion. Optimal expression conditions of cytosolic human AlaRS were found and the procedure for protein purification was conducted, that allows obtaining sufficient amount of protein for further functional investigations. 


\title{
Colocalization of GLG1 protein with Bcr-Abl oncoprotein and its role in the development of chronic myeloid leukemia
}

\author{
M. S. Doroshenko, S. V. Antonenko, G. D. Telegeev, \\ Institute of Molecular Biology and Genetics, NAS of Ukraine \\ 150, Akademika Zabolotnoho Str., Kyiv, Ukraine, 03143 \\ malva0101@gmail.com
}

Introduction. The reason for the progression of chronic myeloid leukemia (CML) is a reciprocal translocation between 9th and 22nd chromosomes, leading to the occurrence of hybrid oncoprotein Bcr-Abl. Due to an increased constitutive tyrosine kinase activity, oncoprotein Bcr-Abl can break proliferation, differentiation, making cells insensitive to the signals from the microenvironment and antiapoptotic signals. In the previous work, we demonstrated an interaction between Bcr-Abl oncoprotein and GLG1 protein. Therefore, the next stage of the research is determining the localization of protein complex GLG1/Bcr-Abl in CML cells and its role in the pathogenesis of CML. Aim. Research of colocalization of GLG1 protein and Bcr-Abl oncoprotein in chronic myeloid leukemia cells. Methods: K562 cells, taken from a patient on a stage of blast crisis, were chosen for the analysis. The localization of proteins was studied via immunofluorescence analysis using specific antibodies anti-Bcr-Abl, anti-GLG1, anti-Golgi Marker, anti-mouse DyLight488, anti-rabbit DyLight550. The results were visualized using confocal laser scanning microscope Zeiss LSM 510 Meta (Germany) with immersion objective 100x1.25 N.A and LSM Browser software. The quantitative analysis was done using the Fiji ImageJ software and the JACoP plugin. Results. Using immunofluorescence analysis with the following confocal microscopy, it was demonstrated that protein GLG1 is located in complex Golgi in K562 cells. The localization signals overlapping GLG1 with oncoprotein were detected in complex Golgi in K562 cells. Using quantitative analysis, we found out that Pearson's Correlation Coefficient reached 0.7 and Mander's colocalization coefficients were 0.905 (M1) and 0.348 (M2). These results affirm a positive correlation and high level of colocalization of target proteins. Conclusions. The colocalization of Bcr-Abl and GLG1 proteins was determined in complex Golgi in CML cells. The hypothetical model of the GLG1 role in CML was proposed. According to it, Bcr-Abl oncoprotein deregulates the properties of GLG1 via phosphorylation, leading to downstream signal pathways damaging, changing the processes of cell mobility, adhesion, migration, and contribution to the disease development. 


\title{
The effect of activated sludge, magnetite, chelated fertilizer on the intergrowth and quality of winter oilseed rape Brassica napus $L$.
}

\author{
S. O. Kovalova
}

National Technical University of Ukraine "Igor Sikorsky Kyiv Polytechnic Institute"

37, Pobedy Av., Kyiv, Ukraine, 03056

svitlayak@gmail.com

\begin{abstract}
Aim. Evaluation of the effectiveness of the use of separated activated sludge as fertilizer for growing industrial crops. Methods. Bioinformatics, high efficiency magnetic separation method, growing plants, determining total iron Results. Bioinformatic analysis of activated sludge microbiota was performed, as a result 26 potential producers of biogenic magnetic nanoparticles $(\mathrm{BMN})$ were found. According to the analysis of total iron, it was found that the spent activated sludge contains a significant amount of iron $\left(9.04 \mathrm{mg} / \mathrm{dm}^{3}\right)$, in comparison with the supernatant liquor $\left(0.84 \mathrm{mg} / \mathrm{dm}^{3}\right)$, which indicates its accumulation in the microorganisms of activated sludge. To compare the effect on germination and growth of Winter Oilseed Rape Brassica napus L., 4 groups of 30 seeds were studied, namely: seeds that germinated and grew without the addition of growth stimulants (control) and, accordingly, with the addition of magnetite nanoparticles by watering with magnetic liquid, in the concentration of $0.1 \mathrm{mg} / \mathrm{ml}$, separated activated sludge and chelated fertilizer, in the concentration of $0.15 \mathrm{mg} / \mathrm{ml}$. The average length of shoots grown with the addition of growth stimulants was $30 \%$ more than in control plants. Also, the survival of plants in the control group for 120 days was only $50 \%$, in contrast to plants grown with the addition of magnetite, separated activated sludge or chelated fertilizer (for them, respectively, $93 \%, 93 \%, 96 \%$ ). Analysis of total iron in the leaves of plants on day 159 of the experiment showed that the iron content in the control was $0.01 \mathrm{mg} / \mathrm{g}$, in plants grown with the addition of magnetite $-0.015 \mathrm{mg} / \mathrm{g}$, with the addition of separated activated sludge $-0.018 \mathrm{mg} / \mathrm{g}$, with the addition of chelated fertilizer $-0.025 \mathrm{mg} / \mathrm{g}$. These data may indicate that the microbiota of activated sludge contains iron in a more accessible form for plants. The addition of spent activated sludge has a positive effect on plant growth, due to the presence of potential producers of BMN. Since the addition of iron chelate to the soil increases the level of BMN synthesis in plants, it can be assumed that BMN microbiota of activated sludge technology has a positive effect on plant growth with such cultivation. Conclusions. Therefore, rapeseed with the addition of magnetite, activated sludge or chelated fertilizer has a stimulating effect on the growth, and increases the germination, development and survival of plants. Most iron was found in the plants watered with chelated fertilizer, less in the plants watered with activated sludge, and even less in plants watered with magnetic liquid containing magnetite nanoparticles. This indicates that the iron in the activated sludge is in the form assimilable by plants. The BMN of activated sludge microbiota has a stimulating effect on plant growth.
\end{abstract}




\title{
Conformational stability and local conformational changes in EMAP II protein studied by long molecular dynamics simulation
}

\author{
D. D. Futornyi, A. I. Kornelyuk \\ Institute of Molecular Biology and Genetics, NAS of Ukraine \\ 150, Akademika Zabolotnoho Str., Kyiv, Ukraine, 03143 \\ futorny_dima@ukr.net
}

\begin{abstract}
Aim. The EMAP II cytokine (endothelial and monocyte-activating polypeptide II) is capable of modulating the properties of endothelial cells, monocytes and leukocytes. Its ability to influence the necrotic processes in tumor cells proves the prospects of creating EMAP II based nanocomposite complexes as potential antitumor agents. The Successful development of EMAP II based antitumor agents requires the investigation of stabilization mechanisms and nanocomposite complex formation at molecular scale. For this purpose, the long molecular dynamics simulation of EMAP II polypeptide was performed in the time range of $750 \mathrm{~ns}$. Methods. The crystalline EMAP II structure with a resolution of 1.8 angstroms (PDB code 1EUJ) was used as an initial structure for molecular dynamics (MD) simulation. All computations were carried out by GROMACS 5.0.7 package with the CHARMM36 force field at $298 \mathrm{~K}$. All MD simulations and analysis were performed using the IMBG computational cluster and MolDynGrid virtual laboratory of Ukrainian National Grid infrastructure (https://moldyngrid.org). Results. For the first time a long MD simulation of EMAP II protein was performed at the $750 \mathrm{~ns}$ interval under physiological conditions. The analysis of the radius of gyration (RG) changes during MD simulation of EMAP II revealed the structure fluctuations in the range of 1.51$1.53 \mathrm{~nm}^{2}$. The absence of significant increase of fluctuations may indicate the stability of protein conformation during MD simulation. This is confirmed by the analysis of the solute accessible surface area (SASA) of protein. Throughout the MD simulation time the SASA fluctuated in the range of 3.5-4.1 nm without significant deviations. However, the analysis of the root mean square fluctuations (RMSF) of EMAP II revealed a higher mobility of Phe110Asp115 and Pro120-Trp125 residues, which correspond to the local microenvironment of the Trp125 residue. The analysis of time-resolved root mean square fluctuations (tRMSF) revealed an increase in fluctuations only for Lys 122 and Lys 121 residues by $130 \mathrm{~ns}$. After $160 \mathrm{~ns}$, this effect extended to Lys123-Glu126 residues. The RMSF value for these residues approaches $0.4 \mathrm{~nm}$ in the $200-430 \mathrm{~ns}$ range and reaches $0.5 \mathrm{~nm}$ in the $430-500,660-670$ and $700-720 \mathrm{~ns}$ time intervals. Conclusions. The analysis of long 750 ns MD trajectory of EMAP II polypeptide revealed high conformational mobility of both Trp 125 residue and its microenvironment, which may be essential for the following binding with the partner molecules during recognition process.
\end{abstract}




\title{
Influence of plant conductive tissue size on its ability to absorb nanoparticles of magnetite
}

\author{
I. V. Demianenko, S. V. Gorobets, O. Yu. Gorobets, S. O. Kovaleva \\ National Technical University of Ukraine "Igor Sikorsky Kyiv Polytechnic Institute" \\ 37, Pobedy Av., Kyiv, Ukraine, 03056 \\ iryna.demjanenko@gmail.com
}

\begin{abstract}
Aim. Magnetic nanoparticles are widely used in various industries, including metallurgy, biotechnology, medicine, agriculture. A large number of studies have been devoted to the influence of magnetic nanoparticles on living systems, but the mechanism of their influence on plant growth and development has not yet been fully revealed. Interaction of magnetic nanoparticles with plant leads to changes in morphology, physiology and biochemistry, which depend on the properties of nanoparticles, including their concentration, dispersion and physical properties, as well as on the type of plant. The interaction between artificial magnetic nanoparticles and biogenic magnetic nanoparticles is practically unexplored. The aim of the work is to study the effect of magnetite nanoparticles on crops taking into account the presence of biogenic magnetic nanoparticles in plants. Methods. In this work, the ability of a number of plants (curly and common parsley, wheat, rapeseed, peas, tomatoes) and fungi (champignons, oyster mushrooms and shiitake) to produce biogenic magnetic nanoparticles was studied with the use of comparative genomics. The cultivation of the studied plants was carried out on the basis of the Department of Bioinformatics of Igor Sikorsky Kyiv Polytechnic Institute. Plants were divided into groups depending on the concentration of magnetite nanoparticles in the soil and control. The analysis of plant parameters (the length of roots and sprouts, plant mass and absolutely dry matter) was performed every 14 days to study the dynamics of magnetite nanoparticles. Results. The conducted bioinformatic analysis showed that all the studied plants are the producers of biogenic magnetic nanoparticles. The study has also shown that the addition of magnetite nanoparticles of different concentrations to the soil significantly affects the growth and development of plants and fungi. Thus, when choosing the optimal concentration of magnetite nanoparticles, flowering and fruit set occur earlier, there is an increase in fruit weight, the root has an increased number of lateral roots, etc. compared to the control. There is an increase in mass of parsley and curly parsley under the action of magnetite nanoparticles at a concentration of $0.1 \mathrm{mg} / \mathrm{ml}$. The same concentration is effective in the cultivation of peas. In tomatoes, similar effects are observed at a concentration of magnetite nanoparticles of $1 \mathrm{mg} / \mathrm{ml}$. Wheat had the best growth rates at a concentration of $0.05 \mathrm{mg} / \mathrm{ml}$ compared to control. There is a significant inhibition of growth of parsley and peas at a concentration of nanoparticles of magnetite $1 \mathrm{mg} / \mathrm{ml}$. Conclusions. Studies have shown a correlation between the maximum concentration of magnetite nanoparticles, which stimulates the growth and development of plants and fungi, and the size of their conductive tissues. The smaller the diameter of the sieve tube, the lower concentration of magnetite should be used to stimulate processes in plants.
\end{abstract}




\title{
Effect of complexes of oligoribonucleotides with D-mannitol on cell cycle and expression of some tlr signaling pathway genes in mouse melanoma B16 cell line
}

\author{
I. M. Kraievska, Z. Yu. Tkachuk \\ Institute of Molecular Biology and Genetics, NAS of Ukraine \\ 150, Akademika Zabolotnoho Str., Kyiv, Ukraine, 03143 \\ ivannakraievska@gmail.com
}

Introduction. Previous studies have shown that the acid form of oligoribonucleotides with D-mannitol (ORN-D-M) inhibits the viability of tumor cells, in contrast to salt. This work aimed to investigate the effect of acidic ORN-D-M on population dynamics, cell cycle, and gene expression of the malignant cell line. Methods. Mouse melanoma B16 cell line was treated with ORN-D-M during 24 and 48 hours with following washing and trypsinization. Microscopic differentiation of living / dead cells was performed using trypan blue. The cell cycle analysis was conducted by the propidium iodide stain method on flow cytofluorimeter. Relative gene expression was investigated by qPCR method. Results. The live/dead cell amount analysis showed a tendency to reduce the number of living cells after 24 and 48 hours of treatment with ORN-D-M compared to the control without treatment. Since the drug is acid by chemical nature, the resistance of cells to acidification of the medium was tested. Thus, at $\mathrm{pH} 6.85$, (which corresponds to the $\mathrm{pH}$ of the nutrient medium with the addition of $5 \mathrm{mg} / \mathrm{ml}$ ORN-D-M) cell viability remains greater than $70 \%$, which is interpreted as the lack of influence of the factor on viability. The study of the cell cycle revealed that the drug affects the ratio of cells in different phases. It was found that in the group with 24-hour treatment an increase in the proportion of cells in the G0/G1-phase by $15 \%$ along with a simultaneous decrease in the S-phase were observed. This result suggests that ORN-D-M may induce an arrest in the G0/G1 phase of the cell cycle. Analysis of the expression of several TLR pathway genes revealed an increase in the relative expression levels of Tlr3, Nfkb1, and Nfkbia, Ifnb1, Ifna2, and Eif2ak. In our opinion, such changes in expression are associated with the activation of the Tlr3 signaling pathway, which leads to the induction of type I interferons. Conclusions. The treatment with ORN-D-M reduces the number of living B16 melanoma cells, and the effect of the drug is not limited to acidification of the nutrient medium. ORN-D-M also affects the changes in the cell cycle and gene expression of the TLR signaling pathway. 


\title{
Monomethine and trimethine cyanine dyes as fluorescence probes for specific nucleic acids visualization in the cell
}

\author{
D. I. Aristova ${ }^{1}$, S. V. Chernii ${ }^{1}$, V. R. Kosach ${ }^{1}$, Y. Slominskii ${ }^{2}$, S. M. Yarmoluk ${ }^{1}$, \\ V. B. Kovalska ${ }^{1}$ \\ ${ }^{1}$ Institute of Molecular Biology and Genetics, NAS of Ukraine \\ 150, Akademika Zabolotnoho Str., Kyiv, Ukraine, 03143 \\ ${ }^{2}$ Institute of Organic Chemistry NAS of Ukraine \\ 5, Murmanska Str., Kyiv, Ukraine, 02660 \\ dar.arist@gmail.com
}

Introduction. Recently, cyanine dyes have become widely used as fluorescent labels and sensors for bioimaging and detecting biomolecules. Therefore, the research aims to study cyanine dyes with different lengths of polymethine chain and substituents as fluorescent probes for visualization of nucleic acid-containing structures and organelles in fluorescence microscopy. Methods. Fluorescence and absorption spectroscopies, fluorescence microscopies were used to characterize spectral-luminescent properties and staining properties of studied dyes. Results. Monomethine cyanine dyes have shown specific fluorescence sensitivity to nucleic acids with increasing emission intensity up to 479 times, with a quantum yield value equal to up to $44 \%$ in the RNA presence. All studied dyes give a stronger response to RNA compared to dsDNA. We have performed staining of live and fixed cells of human breast cancer MCF-7 and human dermal fibroblasts using the most promising dyes. Fluorescence microscopy has shown that all dyes penetrate the plasmatic and nuclear membranes and stain large structures within the nucleus, most probably nucleoli, with a weak fluorescent background in the cytoplasm in both cancer and normal cells. However, the optimal concentrations of the dyes L-29 and Sl-2000 suitable for staining human dermal fibroblasts were up to 200 times higher than that used for MCF-7 cells. We believe that this is due to the presence of a positively charged group in dye structure and thus to different cell permeability because of the membrane charge difference between the cancer and normal cells. Thus, these dyes can be used to selectively stain cancer cells in the presence of normal cells. The obtained results of the RNase A treatment experiment before staining by the dyes allow us to conclude that the studied dyes bind specifically to RNA in the cells (fluorescence almost disappeared after $3 \mathrm{~h}$ of RNase digestion). These data correlate with the spectral-luminescent measurements that showed a higher fluorescent response and, therefore, a higher dye's sensitivity to RNA than to dsDNA. Trimethine cyanine dyes possess low to moderate intensity of fluorescence in a free state but it increases with the addition of nucleic acids up to 83 times in the presence of RNA. Staining of fixed and live MCF-7 cells has shown that these dyes also stain large structures within the nucleus, most probably nucleoli, with a weak fluorescent background in the cytoplasm. Conclusions. Due to a higher cancer cells permeability and sensitivity to RNA, dyes L-29 and Sl-2000 could potentially be used for the cancer diagnostics and biological research. Benzothiazole quinoline cyanines Sl-2598 and Sl-2000 are proposed as efficient high-sensitive stains for nucleoli visualization in live and fixed cells. A series of trimethine cyanines are also proposed for nucleoli visualization in live and fixed cells. In conclusion, we have developed new fluorophores with unique properties that cover green-yellow region of the spectrum. 


\title{
The intron sequence identification of Aegilops tauschii and development of ILP-markers
}

\author{
S. O. Hordynskyi, A. S. Postovoitova, Y. V. Pirko \\ Institute of Food Biotechnology and Genomics, NAS of Ukraine \\ 2A, Osipovskogo Str., Kyiv, Ukraine, 04123 \\ serhiy_hordinskiy@ukr.net
}

\begin{abstract}
Aim. Molecular markers are important tools in both basic and applied genetic research and selection, they are based on variations or polymorphisms in the DNA sequence (Arruda, 2016). Introns are not coding sequences widespread in the genomes of eukaryotes, they are highly polymorphic, which can be used for developing genetic markers. The markers of intron length polymorphism (ILP markers) have such advantages as: genospecificity, codominance, hypervariability. These characteristics are well suitable for mapping molecular markers and investigation of the phylogenetic relationships of related plant species (Rabokon, 2015). The main aim of this study was the identification of intron sequence and the development of ILP markers for the Aegilops tauschii. Methods. In this study we used data bases NCBI, Phytozome and programs CD-HIT and Primer3Plus. Results. To develop ILP markers, we had to specify the name of the culture Aegilops tauschii in the NCBI database in the search field and to select EST on the left. Next, one should click "Send to:" and select format "FASTA to receive the resulting file containing 208 EST sequences, without introns. To get rid of repetitions, we used the CD-HIT Suite program and chose cd-hit-est. In the new window, the file is specified with the required EST sequences, and the settings are left by default. As a result, the file with 181 sequences was obtained. To identify the theoretical location of the introns, we compared the resulting sequences with the rice genome using the BLAST tool on the Phytozome site. On the main page of the site one should press the "Tools" key and select "BLAST". The new page on the left indicates the culture to be compared with, and on the right side, one sequence from the document obtained in the CD-HIT Suit program is inserted, and then one should press a small key on the right side of "Go". As a result, if there is a similar sequence, two sequences will be represented: the sequence, for which the intron search is performed in the form of a gap, and the culture sequence with which the comparison was performed, respectively. Out of 181 sequences, 120 were similar to rice genes, 14 of which were theoretically found at the intron locations. The primers were selected using the program Primer3Plus. To do this, one should copy the sequence into the appropriate field and take in square brackets the theoretical location of the intron 1-2 nucleotides. As a result of this work, 17 pairs of primers for the intron sequences of Aegilops tauschii were developed. Conclusions. Using bioinformatics approaches, specific markers for Aegilops tauschii were developed for the first time, which are planned to be further used to study the genetic diversity of this and other species of the genus Aegilops.
\end{abstract}




\title{
Expresion, purification and in vitro characterization of long isoform of translation elongation factor EEF1B $\beta$ from human
}

\author{
N. T. Kolodka, V. F. Shalak, B. S. Negrutskii \\ Institute of Molecular Biology and Genetics, NAS of Ukraine \\ 150, Akademika Zabolotnoho Str., Kyiv, Ukraine, 03143 \\ nazarkolodka2000@gmail.com
}

Background. eEF1B $\beta \mathrm{L}$ is a long isoform of translation elongation factor eEF1B $\beta$ that mediates the GDP/GTP exchange in eEF1A in higher eukaryotes. Expression of the long isoform is restricted to brain, cerebellum and testis. mRNA is produced via alternative splicing from the eEF1B $\beta$-encoding EEF1D gene. In eEF1B $\beta \mathrm{L}$ mRNA an additional 3 exon is included containing a nuclear localization signal. Consequently, eEF1B $\beta \mathrm{L}$ in mammalian cells can act as a transcription factor of genes with the heat-shock response elements. The three-dimensional structure of full-length eEF1B $\beta$ is not known, whereas the spatial organization of its C-terminal domain was solved by NMR. The structure of the other part of eEF1B $\beta$ and eEF1B $\beta L$ that has a long insertion remains to be established. Thus, the aim of our work was to express cDNA encoding eEF1B $\beta \mathrm{L}$ in bacterial cells, purify the target protein to homogeneity and analyze it by different methods. Methods. Recombinant fusion proteins GST-eEF1B $\beta L$ and 6xHis-eEF1B $\beta$ L were synthesized in E.coli strain BL21(DE3)pLysS and purified on glutathione-agarose and Ni-NTA columns, respectively. The GST-tag was removed by PreScission protease. The molecular mass and aggregate state of the purified proteins were determined by analytical gel filtration. The presence of disordered region(s) within eEF1B $\beta \mathrm{L}$ was predicted by the PrDOS server and the atomistic structural models were built by I-TASEER. Results. As a result we showed that GST-eEF1B $\beta$ L and 6xHis-eEF1B $\beta$ L were successfully produced in bacteria as soluble proteins. Affinity chromatography for both proteins was performed in the native conditions using glutathione agarose and $\mathrm{Ni}$-immobilized resin, respectively. The protein yield was about $1-2 \mathrm{mg} / 100 \mathrm{ml}$ of culture and purity was about $80 \%$ according to SDS-PAGE. Treatment of GST-eEF1B $\beta$ L by PreScission protease led to partial eEF1B $\beta L$ precipitation. The remaining soluble fraction of protein formed the aggregates more than $1 \mathrm{MDa}$ as jugged by the analytical gel filtration. Affinity purified $6 \times \mathrm{xHis}-\mathrm{eEF} 1 \mathrm{~B} \beta \mathrm{L}$ also formed heavy aggregates. Purification of 6xHis-eEF1B $\beta \mathrm{L}$ in the denaturing conditions resulted in a higher yield of the target protein, however, subsequent elimination of denaturing agent led to formation of the soluble heavy aggregates. The PrDOS server predicted the existence of a very long disordered region in the N-terminal part of eEF1B $\beta$ L. Modeling of the eEF1B $\beta$ L tertiary structure by I-TASEER confirmed the PrDOS prediction. Conclusions. We conclude that eEF1B $\beta \mathrm{L}$ belongs to the family of intrinsically unstructured proteins that tend to aggregate and precipitate in vitro and, thus, is inappropriate for structural studies using X-ray diffraction or NMR. 


\title{
Chromatographic fractionation of ORNS-D-Mannitol mixture
}

\author{
A. O. Nuzhny, R. O. Nikolaiev, Z. Yu. Tkachuk \\ Institute of Molecular Biology and Genetics, NAS of Ukraine \\ 150, Akademika Zabolotnoho Str., Kyiv, Ukraine, 03143 \\ alexnuzhny@gmail.com
}

The aim of the research was to separate] oligoribonucleotides into fractions and to prove their different properties by spectral methods. It was shown that the complexes of oligoribonucleotides and D-mannitol have antiviral, anti-inflammatory and immunomodulatory activities. They are a mixture of oligoribonucleotides of various lengths and sequences, therefore, we tried to divide them into smaller fractions for the study. Materials and methods. For separation, we used a mixture of ORNs-D-mannitol, which was separated by the method of size exclusion chromatography with a stationary phase Sephadex G-50 (cross-linked dextran gel). The received fractions were analyzed by absorption and fluorescence spectroscopy. The biological activity of the fractions was investigated. Results. As a result of the study, a quantitative chromatographic system was selected (Isocratic elution mode, stationary phase - Sephadex G-50, mobile - Phosphate buffered saline, PBS pH =7), and the methods were approximated. The concentrations were adjusted to a single adsorption value and a correlation of fluorescence with decreasing molecular size was obtained. That way we were able to prove the separation of the master batch into several fractions. The Excitation Emission Matrix (EEM) has been obtained. Conclusion. The ORNs-D-mannitol mixture was divided into several heterogeneous fractions that differ in their spectral characteristics. 


\title{
Merocyanine dyes as fluorescent probes for microscopy and detection of proteins
}

\author{
A. T. Syniugina ${ }^{1}$, S. V. Chernii ${ }^{1}$, A. A. Mokhir ${ }^{2}$, V. B. Kovalska ${ }^{1}$, S. M. Yarmoluk ${ }^{1}$ \\ ${ }^{1}$ Institute of Molecular Biology and Genetics, NAS of Ukraine \\ 150, Akademika Zabolotnoho Str., Kyiv, Ukraine, 03143 \\ ${ }^{2}$ Friedrich-Alexander-University of Erlangen-Nuremberg \\ 42, Henkestr, Erlangen, Germany, 91054 \\ agness_s@ukr.net
}

Introduction. Visualization of cell components or study of compound distribution in cells is widely used to research different biological processes. It is important that fluorescent labels can visualize organelles or molecules with desirable properties such as emission at the far-red region to minimize biological background fluorescence. Therefore, the aim of our work is the synthesis and investigation of the spectral-luminescent properties of novel far-red dyes with carboxyl substituents that makes it possible to use these dyes as fluorescent labels being covalently attached via this group. Methods. Spectral-luminescence properties of dyes were investigated by fluorescent spectroscopy and UV-VIS absorption measurements. Staining the cells with the dyes was studied by the method of fluorescence microscopy. Results. Spectralluminescent properties of merocyanine dyes were measured in the aqueous buffer and in the presence of some global proteins. The fluorescence emission maxima lie in the far-red area of the spectrum between 640 and $730 \mathrm{~nm}$. The dyes are characterized by low quantum yield values in a free state. However, the addition of serum albumins leads to an increase in the quantum yields of the studied dyes by 8-30 times and to the shift of emission maxima to the long-wavelength spectral region. To study the ability of the selected synthesized dyes to penetrate cell membrane and their applicability as probes for fluorescence imaging of living cells, the human ovarian cancer A2780 cells were used. All measurements were carried out in HBSS buffer, since the dyes in the medium containing FBS did not penetrate and stain the cells, probably due to their binding to albumin. The blue fluorescent dye Hoechst 33342 binding to nuclear DNA was used for the nucleus co-staining, and Rodamine 123 (a dye specific for mitochondria) was used to understand the organelle-specificity of dyes. It has been shown that dyes did not accumulate in nuclei: they partially colocalize with Rhodamine 123, and therefore do stain mitochondria, as well as some other organelles in the cytoplasm. The lack of specificity of dyes to some specific components of the cell (for example, mitochondria) may be an advantage for this class of compounds in their use as the probes for studying the drugs distribution. However, the studied dyes bleached quickly with irradiation under these experimental conditions, which could limit their practical use. Conclusions. The novel dyes are suggested as promising far-red probes for the serum albumins detection. The novel series of merocyanine dyes could be potentially applicable in fluorescent spectroscopy for visualization with minimum to no auto fluorescence. Also, it has been shown that the dye is not specific to the tested elements of the cytoplasm, which makes these dyes promising for use as the probes for studying drug distribution. 


\title{
The effectiveness of antibiotics in the collagen matrix against opportunistic pathogens
}

\author{
L. O. Lastovetska, V. I. Maslak, O. S. Iungin \\ Kyiv National University of Technologies and Design \\ 2, Nemirovich-Danchenko Str., Kyiv, Ukraine, 01011 \\ liudmyla.last@gmail.com
}

\begin{abstract}
Aim. The aim of the study was to determine the effectiveness of antibiotics - chloramphenicol (CP) and azithromycin (AZM) - in collagen matrix against opportunistic pathogens. Methods. The 96-well microtiter plate assay was used. The overnight cultures (NB, HiMedia Ltd.) of laboratory strains $E$. coli, $K$. pneumoniae, $S$. aureus were inoculated (1:10 ratio) in plates containing collagen matrices with CP ethanol solution $(1-4 \mathrm{mg} / \mathrm{ml})$ and AZM water solution $(1-10 \mathrm{mg} / \mathrm{ml})$. There was also a positive control for CP test $-96 \%$ ethanol. The strains were cultivated 24 hours at $37{ }^{\circ} \mathrm{C}$. The OD600 was measured and the crystal violet assay was applied. Results. It was shown that both studied antibiotics have a wide range of antibacterial activity. The effectiveness of AZM against both gram-negative and gram-positive cultures was shown at the concentration of $10 \mathrm{mg} / \mathrm{ml}$. The number of survived cells was $12.2[12.1 ; 12.4] \%, 18.4[18.2 ; 18.5] \%$ та $1.9[1.9 ; 1.9] \%$ for E. coli, K. pneumoniae, S. aure$u s$, respectively. It was also shown a total growth inhibition (up to $99 \%$ of cells) of all tested strains in the presence of $1 \mathrm{mg} / \mathrm{ml} \mathrm{CP}$. However, almost the same results (cells inhibition 95.1-98.7\%) were obtained in positive control with $96 \%$ ethanol. So there was no possibility to differentiate the effectiveness of $\mathrm{CP}$ itself and the solvent. Conclusions. The results of the study indicate that both antibiotics can be used as an antibacterial component in collagen matrices.
\end{abstract}




\title{
Study of the magnetophoretic mobility of probiotic cultures for their use in targeted drug delivery
}

\author{
L. V. Kuzminikh, S. V. Gorobets, O. Yu. Gorobets \\ National Technical University of Ukraine "Igor Sikorsky Kyiv Polytechnic Institute" \\ 37, Pobedy Av., Kyiv, Ukraine, 03056 \\ l.kuzminykh-2022@kpi.ua
}

Aim. Recently, probiotics have been widely studied as the vectors for targeted drug delivery in the treatment of cancer and pathological conditions of gastrointestinal tract [1]. Methods. Selection of microorganisms was carried out using bioinformatics analysis. Microorganisms were grown on agar media for $48 \mathrm{~h}$ at a temperature of $36 \pm 1{ }^{\circ} \mathrm{C}$. The medium was modified using iron chelate (ST+Fe-EDTA) at a concentration of $64 \mathrm{mg} / \mathrm{L}$. Cultivation conditions were also changed[. The petri plates with cultures of microorganisms were introduced into a permanent magnetic field (PMP). Magnetophoretic mobility was studied using a system of two permanent magnets [2]. Thus, microorganisms grown under different conditions were studied: control — standard (ST), with the addition of iron chelate (ST+Fe-EDTA), in PMP (ST+M), and with the addition of iron chelate grown in PMP $(\mathrm{ST}+\mathrm{Fe}-\mathrm{EDTA}+\mathrm{M})$. Results. According to the analysis of available probiotic drugs, as well as bioinformatics analysis, 2 strains were selected: Lactobacillus rhamnosus GG and Streptococcus thermophilus TH-4. Bioinformatics analysis has shown that GG can be a producer of intracellular amorphous biogenic magnetic nanoparticles (BMN), whereas TH-4 - extracellular amorphous BMN. The relative speed of movement of particles in the GG-suspension increased as compared with the control (ST): by 1.5 times for $\mathrm{ST}+\mathrm{M}, 5$ times for $\mathrm{ST}+\mathrm{Fe}-\mathrm{EDTA}$ and 6 times for $\mathrm{ST}+\mathrm{Fe}-\mathrm{EDTA}+\mathrm{M}$. The relative velocity of the TH-4 suspension particles increased as compared with the control: by 1.3 times for $\mathrm{ST}+\mathrm{M}, 1.7$ times for ST+Fe-EDTA and 2 times for $\mathrm{ST}+\mathrm{Fe}-\mathrm{EDTA}+\mathrm{M}$. Conclusions. The difference in the velocity results for the strains GG and TH-4 can be explained by the fact that they produce different properties of BMN. Thus, this technique of enhancing ferrimagnetic properties can be used to create the vectors for targeted delivery of drugs based on BMN, which will be more effective compared to the microorganisms grown by standard methods [3]. It is also a promising method for combining targeted drug delivery with magnetic hyperthermia, which will increase its effectiveness [4].

1. Legesse Bedada T. et al. Probiotics for cancer alternative prevention and treatment. Biomed. Pharmacother. 2020; 129: 110409.

2. Gorobets S. V. et al. Magnetically controlled vector based on E. coli Nissle 1917. 2020.

3. Aziz Mousavi S.M.A. et al. Characterization of biosynthesized silver nanoparticles using lactobacillus rhamnosus GG and its in vitro assessment against colorectal cancer cells.Probiotics Antimicrob. Proteins. 2020: 12 (2): 740-6.

4. Chang D. et al. Biologically targeted magnetic hyperthermia: potential and limitations. Front. Pharmacol. 2018: 9. 


\title{
Petri plates definition of appropriate primers for detection of the S65TPGFP gene in plants by PCR
}

\author{
V. O. Pelypenko, I. O. Nitovska, B. V. Morgun \\ Institute of Cell Biology and Genetic Engineering, NAS of Ukraine \\ 148, Akademika Zabolotnogo Str., Kyiv, Ukraine, 03680 \\ pelypenko.vadym@lll.kpi.ua
}

Introduction. The synthetic reporter $S 65 T p g f p$ gene of green fluorescent protein (GFP) constructed via replacement of the serine at position 65 with threonine (S65Tpgfp) is used in genetic constructs for the screening of transformation events. Because the primers can have an affinity for used DNA that could lead to polymerization of an inappropriate amplicon, it is important to have a reliable pair of primers to identify the transgene in the DNA of the species under study. The aim of work was to test the efficiency of several primer pairs for detection of the S65Tpgfp gene in transgenic plants of tobacco and maize and to select the most appropriate one for analyses of plants by polymerase chain reaction (PCR). Methods. The total DNA isolated from leaves of tobacco and maize regenerants obtained after Agrobacteriummediated transformation using pCB271 vector, as well as the untransformed plants have been analyzed by PCR method. Three pairs of primers were used to detect the S65Tpgfp gene in the plant DNA: 1) $g f p$ 2F-2R (gfp 2F: 5'-GACGT GAACG GCCAC AAGTT CA-3', $g f p$ 2R: 5'-CGATG CGGTT CACCA GGGTG T-3'), expected amplicon 311 bp; 2) gfp 3F-3R (gfp 3F: 5'-ATGCC ACCTA CGGAA AGCTC-3', gfp 3R: 5'-GATGC GGTTC ACCAG GGTAT-3'), $263 \mathrm{bp} ; 3) g f p$ 4F-4R ( $g f p$ 4F: 5'-ACTAC AAGAC ACGTG CCGAA-3', gfp 4R: 5'-TGTGG TCCCT CTTCT CGTTG-3)', $339 \mathrm{bp}$. As a positive control the total DNA of the tobacco plant containing the S65Tpgfp gene was used. The negative control was DNA of untransformed plants, as well as DNA free sample. The amplification program for detection of the S65Tpgfp gene was given as follows: $94{ }^{\circ} \mathrm{C}$ for 4 min followed by 34 cycles $94{ }^{\circ} \mathrm{C}$ for $30 \mathrm{~s}, 58{ }^{\circ} \mathrm{C}$ for $30 \mathrm{~s}, 72{ }^{\circ} \mathrm{C}$ for $25 \mathrm{~s}$. The amplification products were separated by electrophoresis in $0.8 \%$ agarose gel with bromine ethidium $(0.5 \mu \mathrm{g} / \mathrm{ml})$ in Lithium Borate buffer. Results. Analyzing the obtained electrophoregrams, we did not observe any band on the tracks with negative controls. More than one amplicons were observed in some samples containing maize DNA when using the $g f p 2 \mathrm{~F}-2 \mathrm{R}$ primers. It indicates low specificity of this primer pair in the case of maize DNA analyzes. The distinct amplicon was observed after using $g f p 3 \mathrm{~F}-3 \mathrm{R}$ or $g f p$ $4 \mathrm{~F}-4 \mathrm{R}$ primer pairs of 263 or $339 \mathrm{bp}$ in length consequently. So a small size of the amplicon obtained using the gfp $3 \mathrm{~F}-3 \mathrm{R}$ primer pair may be masked by low molecular front, thus, the using of the gfp $4 \mathrm{~F}-4 \mathrm{R}$ pair is optimal for analysis of maize and tobacco transformants containing the $S 65 \operatorname{Tg} f p$ gene. Conclusions. It has been shown that the gfp 4F-4R pair of primers is the most appropriate for detection of the S65Tpgfp gene in the transgenic plants, both tobacco and maize. 


\title{
Influence of thiosulfonates on the activity of antioxidant protection enzymes in rat liver
}

\author{
N. M. Liubas, N. M. Liubas, R. Ya. Iskra \\ Institute of Animal Biology, NAAS of Ukraine \\ 38, Stusa Str., Lviv, Ukraine, 79034 \\ n_lubas@ukr.net
}

Introduction. Structural analogs of natural organic sulfur-containing compounds are S-alkylesters of thiosulfonic acids of general formula R-S (O)2S-R': S-ethyl-4aminobenzenethiosulfonate (ETC), S-allyl-4-aminobenzenethiosulfonate (ATC), 4-allylacetylaminobenzene thiosulfonate (AATS), synthesized at the Department of Technology of Biologically Active Compounds, Pharmacy and Biotechnology of Lviv Polytechnic National University. They are characterized by a wide range of biological action, which often exceeds the effectiveness of natural structural analogs such as garlic, onion, and cabbage. They showed good results as promising antimicrobial substances [Lubenets, 2017]. Our study aimed to determine the effect of thiosulfonates on the state of the antioxidant defense system in the liver of rats. Methods. The study was performed on male laboratory rats, divided into four groups of 5 animals each: group I — control, II, III, IV — experimental. The diet of animals in the control group was supplemented with $0.5 \mathrm{~cm}^{3}$ of oil once a day; in II, III, IV groups with $0.5 \mathrm{~cm}^{3}$ of oil solution ETS, ATS, AATS (concordantly) at the rate of $100 \mathrm{mg} / \mathrm{kg}$ body weight. The experiment lasted 21 days. The levels of superoxide dismutase (COD), catalase (CAT), glutathione peroxidase (GP), glutathione reductase (GR), reduced glutathione (GSH), and TBA-active products were determined in rat liver homogenates. The obtained digital data were processed statistically using Microsoft EXCEL by the the one-way ANOVA method. Results. As a result of studies, we found a slight increase in the content of TBA-active products in the liver homogenates of the animals of II, III, IV experimental groups by $7 \%, 14 \%$, and $6 \%$, respectively, compared with the control group. The activity of antioxidant enzymes increased compared to the control group SOD - by $19 \%$ (II), $11 \%$ (III), $6 \%$ (IV), CAT by $20 \%$ (II), $10 \%$ (III), $8 \%$ (IV). The activity of the enzymes of glutathione link in the antioxidant protection decreased in all experimental groups compared with the control. Conclusions. Feeding animals with thiosulfonate was accompanied by an increase in the content of TBA-active products and HPL, activation of CAT and SOD enzymes, inhibition of GP, GR, GSH. These results may indicate that the increased amount of TBA-active products and HPL is associated with the activation of LPO and possibly with the synthesis of eicosanoids, which are the elements of manifestation of the general nonspecific adaptation syndrome. In this process, the intermediates are lipid hydroperoxides, TBA-active products. Accordingly, in the catabolic phase, which likely occurs with the consumption of thiosulfonates and the decay of organic molecules, the synthetic processes take place - eicosanoids are formed to help to overcome stress lipid peroxides, and the TBA-active products are not metabolized. 


\title{
Differential effects of S6K1 isoforms on EMT-related gene expression in $\mathrm{MCF}-7$ cells
}

\author{
A. V. Mazov \\ Institute of Molecular Biology and Genetics, NAS of Ukraine \\ 150, Akademika Zabolotnoho Str., Kyiv, Ukraine, 03143 \\ andriy.mazov@gmail.com
}

Introduction. Based on expression profiling, the breast cancer tumors are generally divided into 4 molecular subtypes: luminal A, luminal B, HER2-enriched, and triple-negative. The triple negative subtype remains by far the most clinically challenging. It is characterized by the lack of estrogen and progesterone receptor expression. It also lacks overexpression of HER2 and demonstrates the epithelial-to-mesenchymal transition (EMT). Ribosomal S6 kinase 1 (S6K1), a downstream effector of mTOR is known to be involved in tumor progression. There are 3 active S6K1 isoforms known to date: $\mathrm{p} 85, \mathrm{p} 70$, and $\mathrm{p} 60$. To further elucidate the role of $\mathrm{S} 6 \mathrm{~K} 1$ isoforms in the progression of breast carcinomas the following knockout cell lines (generated previously in our department) were studied: MCF-7 F1 (p85-, p70 $\mathrm{F} 2\left(\mathrm{p} 85^{-}, \mathrm{p} 70^{-}, \mathrm{p} 60^{+}\right), \mathrm{MCF}-7 \mathrm{~F} 3\left(\mathrm{p} 85^{-}, \mathrm{p} 70^{-}, \mathrm{p} 60^{-}\right)$. The aim was to analyze the differential impact of S6K1 isoforms on the expression of EMT-related genes. Methods. Using RT-qPCR the expression levels of 29 genes were analyzed. The following genes were selected for study: ESR1, MYB, HIF1A, NF-kB p65, KLF4, SOX2, ZEB1, STAT3-1, STAT3-2, NRF2, OCT4, MYC, NF-kB p50, TJP1, CFL1, TNF- $\alpha$, IL6, MMP2, MMP9, SNAI1, TWIST1, KLF17, CCL2, ITGB1, NANOG, MMP1, CTSD, MMP14, ZEB2. Results. In MCF-7 F2 (p85-, p70-, p60+) $H I F 1 A, M Y C, T N F-\alpha$ were downregulated 4.9, 4, and 19.7-fold respectively whereas TJP1, TWIST1, CCL2, CTSD, MMP14, and ZEB2 were upregulated 119, 300, 51, 6.87, 40 and $18 \times 10^{3}$-fold respectively. Conclusion. These data are consistent with the fibroblast-like morphology and motility of the MCF7 F2 (p85-, p70-, p60 $)$ cells and suggest the involvement of p60S6K1 isoform in EMT. 


\title{
Interaction specificity of N-stop with scaffold protein ITSN1 is mediated by its $\mathrm{C}$-terminal domain
}

\author{
I. S. Voloshyn, D. Y. Morderer, A. H. Boshtova, R. O. Nikolaiev, K. V. Onyshchenko, \\ I. Y. Skrypkina \\ Institute of Molecular Biology and Genetics, NAS of Ukraine \\ 150, Akademika Zabolotnoho Str., Kyiv, Ukraine, 03143 \\ vanya0107@gmail.com
}

\begin{abstract}
Aim. MAP6 (STOP) protein plays a major role in stabilization of neuronal microtubules and, as a result, in neuronal differentiation, development and functioning. Malfunctions in the expression of this protein lead to behavioral and cognitive disorders. Neurons contain two major isoforms of the protein: neuronal (N-STOP) and embryonal (E-STOP). E-STOP isoform has all the required components to maintain the ability to stabilize microtubules. However, the $\mathrm{N}-\mathrm{STOP}$ isoform that differs from the E-STOP by having the additional $\mathrm{N}$ aminoacids at the C-terminus is predominantly expressed during post-embryonic development. Scaffold protein intersectin 1 (ITSN1) also plays a major role in the functioning and development of neurons. Previous researches have shown that ITSN1 interacts with STOP proteins, especially with $\mathrm{N}-\mathrm{STOP}$. We assume that N-STOP C-terminal domain plays a major role in this interaction. That's why the aim of this work is to research the specificity of interaction between ITSN1 and N-STOP, [and to] determine the structure of C-terminal domain and its role in this interaction. Methods. Coding sequences of N - and E-STOP isoforms have been cloned in pcDNA4/ His MaxA expression vectors. Interaction of individual ITSN1 GST-SH3 domains with the STOP isoforms was tested by in vitro binding assay with 293 cell line lysates, transfected with the obtained constructions. Bound proteins were analyzed by Western blot. GST and GST-fused SH3 domains were stained with Coomassie brilliant blue. C-terminal domain of N-STOP was cloned in pET28c vector and purified using affinity chromatography on Ni-NTA agarose. Its secondary structure was determined using circular dichroism spectroscopy with further analysis using BeStSel server. Results. GST pulldown assay showed that N-STOP binds the ITSN1 SH3A domain with higher affinity than E-STOP. We assume that specificity of N-STOP interaction with SH3A ITSN1 is due to its C-terminal domain that is absent in E-STOP. The analysis of secondary structure of N-STOP C-terminal domain predicts the existence of antiparallel $\beta$-sheets (45.1\%) and $\beta$-turns (13.6\%) in its structure. Other structures occupy $41.3 \%$ of this fragment. Moreover, protein contains two ordered regions that are located in the regions of 43-115 and 210-230 aminoacid residues. Because it is known that $\beta$-sheets have a tendency to bind to each other, the non-specific binding of this type with other proteins can form the aggregates and fibers that are typical for several diseases, e.g. amyloidosis. As it was previously shown, in some diseases, e.g. amyotrophic lateral sclerosis, STOP forms aggregates with neurofilaments in affected axons. Conclusions: It was shown that specificity of neuronal forms of STOP and ITSN1 protein interaction is due to N-STOP C-terminal fragment. The study of the secondary structure of the N-STOP C-terminus predicts the presence of disordered regions and $\beta$-sheets.
\end{abstract}




\title{
Intraspecific differentiation of Viscum album $\mathrm{L}$. using the analysis of intron length polymorphism of $\beta$-tubulin genes
}

\author{
A. S. Postovoitova, A. M. Rabokon, Yu. O. Bilonozhko, L. O. Kalafat, Ya. V. Pirko \\ Institute of Food Biotechnology and Genomics, NAS of Ukraine \\ 2A, Osipovskogo Str., Kyiv, Ukraine, 04123 \\ nastya.postovoytova@gmail.com
}

Introduction. White mistletoe (Viscum album L.) belongs to the genus Viscum, which parasitizes on diverse of woody plant species. $V$. album is thought to cause growth retardation and premature defoliation, to reduce the area of photosynthesizing tissues, and to alter the water and carbon balance of host trees, which, in turn, leads to lower resistance of woody plants to other damaging factors (Barbu, 2012). Three white mistletoe subspecies are the most widely recognized: $V$. album ssp. abietis (Wiesb.) Abromeit is met on silver fir (Abies ssp.); V. album ssp. austriacum (Wiesb.) Vollmann mainly dwells on pine trees (Pinus ssp.), and V. album ssp. album L. grows on diverse of deciduous woody species (Bohling et al., 2002). However today the $V$. album taxonomy remains inconsistent, and there is no thorough study of various subspecies using molecular markers. Therefore, the aim of this study was to identify the molecular genetic differences among white mistletoe which grows on plants of different woody species. Methods. The study material included $V$. album samples collected from ten trees of each species (silver maple (Acer saccharinum L.), Scots pine (Pinus sylvestris L.) and European silver fir (Abies alba L.)). The analysis was performed using the marker system based on determining the intron length polymorphism of the $\beta$-tubulin genes (Tubulin Based Polymorphism, TBP) (Bardini et al., 2004). Genomic DNA was extracted from leaf plates according to the CTAB method (Green et al., 2012). PCR products were separated by electrophoresis on a $6 \%$ denatured polyacrylamide gel and visualized by silver nitrate staining. Results. Using TBP method we obtained DNA profiles of all mistletoe samples, which contained intron fragments of length from $200 \mathrm{bp}$ to $2000 \mathrm{bp}$. The vast majority of amplicons were common to all samples, indicating belonging to the same species $V$. album. Differences were detected between the molecular profiles of mistletoe samples from maple, fir and pine trees, although these samples had two common monomorphic fragments sized approximately $386 \mathrm{bp}$ and $650 \mathrm{bp}$. The fingerprinting data on intron I of the $\beta$-tubulin gene were used for the cluster analysis. All investigated samples were divided into three groups. Each group was formed by the samples of mistletoe growing on different host trees. Conclusions. Based on the analysis of intron I length polymorphism of the $\beta$-tubulin genes (TBP analysis), the differences between three mistletoe subspecies (V. album ssp. austriacum (Wiesb.), V. album ssp. abietis (Wiesb.) and V. album ssp. album L.) have been shown. The possibility of using TBP analysis for the intraspecific differentiation in mistletoe plants has been also demonstrated. 


\title{
Investigation of posttranscriptional regulation of genes involved in cytoskeleton dynamics
}

\author{
A. O. Hubiernatorova, D. O. Gerasymchuk, S. V. Kropyvko \\ Institute of Molecular Biology and Genetics, NAS of Ukraine \\ 150, Akademika Zabolotnoho Str., Kyiv, Ukraine, 03143 \\ april.scorpionen@gmail.com
}

Introduction. Cytoskeleton remodeling is an essential physiological process that allows multiple cellular activities such as division, migration, endo - and exocytosis and others. Deregulation of the genes involved in these processes plays an important role during multiple pathological processes, for example malignization. Although there are multiple studies characterizing the orchestrating of cytoskeleton dynamics there is still a lot of gaps in understanding how it is regulated posttranscriptionally. The study aimed to find possible mechanisms of posttranscriptional regulation of genes involved in cytoskeleton dynamics, namely those participating in the actin-rich protrusions formation at normal and pathological conditions with further in vitro verification of microRNA binding sites in 3'UTR of ITSN1. Methods. We used multiple bioinformatical resources for the analysis of target transcripts' 3'UTRs, eukaryotic cell cultivation, luciferase assay and western-blot analysis for investigation on microRNA effects. Results. At the first stage of analysis we scanned transcriptional isoforms of 37 genes for regulatory motifs (binding sites for microRNAs and RNA-binding proteins in their 3'UTRs) that can influence mRNA stability and translation. The results have shown that for RBPs there are 2 major common regulatory elements: AU-rich elements and binding sites for MSI proteins. AU-rich elements are the binding sites for different RBPs, among which TTP, the protein that destabilizes its target mRNAs thus inhibiting the protein production. Since TTP is localized both in nucleus and cytoplasm we analyzed the probability of TTP binding to transcripts of TKS4, TKS5, ITSN1, ITSN2, N-WASP and WIP and predicted that TTP can interact with ITSN1, TKS5 and WIP mRNAs and with proteins, which can reveal novel mechanisms of their functioning and regulation. We also found that there are few common microRNA binding sites for TKS4, TKS5, ITSN1, ITSN2, N-WASP and WIP , among which for further investigation we chose microRNAs 181a, 19a and 30a. Due to the luciferase test assay, the binding sites for microRNAs 181a and 19a in 3'UTR of ITSN1-S are functional and downregulate its expression, although western-blot analysis showed that the protein level of ITSN1 does not significantly change after $48 \mathrm{~h}$ of transfection, probably after $48 \mathrm{~h}$ there is still a protein product synthesized before the transfection. We also checked the N-WASP protein level after transfection of microRNA-181a and found that it was significantly lower compared to the negative control that may suggest that the binding site for microRNA-181a in $N$-WASP 3'UTR is also functional. Nevetheless, further investigation is needed. Conclusions. The obtained data show the importance and high potential of studying the mechanisms of posttranscriptional regulation of the genes involved in cytoskeleton dynamics to improve our understanding of these processes. 


\title{
Protein-protein interactions and phosphorylation of verproline family member - CR16
}

\author{
K. D. Lavrynenko, S. V. Kropyvko \\ Institute of Molecular Biology and Genetics, NAS of Ukraine \\ 150, Akademika Zabolotnoho Str., Kyiv, Ukraine, 03143 \\ kirlavrinenko@gmail.com
}

Adaptor protein CR16 is a verproline family member, which includes - CR16, WIP and WIRE. This family of proteins is known to contribute to Arp $2 / 3$ dependant actin polymerization. While the most known white mistletoe verprolines, such as WIP, are recognized to play an important role in the actin restructuration, the key process of invadopodia and podosome formation, other members, such as CR16 protein are far less studied. It is known that CR16 is expressed in brain tissue as well as in testes, and may be involved in spermatogenesis, due to its knockout being a reason for abnormal spermatogenesis of Sertoli cells. The study aimed at the investigation of CR16 protein-protein interactions with SH3 containing proteins, namely those involved in signal transduction and the formation of invadopodia and also the possibility of its phosphorylation by SRC kinase. Methods: We used molecular cloning techniques, eukaryotic cell cultivation for generation of proteins for analysis, GST-Pull down was used to detect protein-protein interactions, immunoprecipitation was used for phosphorylation analysis, Western-Blot was used for visualization of experiments. Results: At the first stage we selected a variety of SH3 domain-containing proteins: AMPH1, BIN1 — involved in vesicle recycling, PLCg1, SRC (omnipresent and neuronal isoforms, CSK - signal transduction, small adaptor proteins CRK, GRB2. The Obtained data showed that CR16 interacts with SH3 domains of AMPH1, CRK, GRB2, CTTN, PLCg1 and both SRC and SRC neuronal. Also CR16 interacts strongly with SRC kinase and GRB2 while being in complex with $\beta$-actin. Furthermore, we checked if CR16 is phosphorylated by SRC-kinase. The results obtained here showed, that indeed CR16 was phosphorylated by SRC kinase in one or more of 4 different tyrosine sites. Knowing that two sites of tyrosine phosphorylationare located in WASP and N-WASP binding domains, we checked if CR16 phosphorylation affects said interaction. The obtained results showed that CR16 phosphorylation does not affect the CR16-WASP/N-WASP interaction. Conclusions: We discovered 8 new partners of CR16 protein and showed strong interactions between CR16/ $\beta$-actin complex and SRC-kinase, as well as GRB2 small adaptor protein. This finding may suggest new variety of the CR16 potential roles, including signal transduction and vesicle recycling. CR16 is phosphorylated by SRC-kinase, moreover this process may be tied to CR16 being in the complex with $\beta$-actin, because neuronal isoform of SRC-kinase was shown to bind CR16 but not CR16/ $\beta$-actin complex. 


\section{Dynamic alterations of immunophenotype, $C$ reactive protein and interleukine-6 levels in peripheral blood of severe COVID-19 patients}

T. V. Bukreieva1, V. V. Nikulina², I. Ya. Skrypkina ${ }^{1}$, V. M. Kyryk ${ }^{3}$, A. R. Vega ${ }^{4}$,

O. L. Chybisov ${ }^{5}$, O. V. Duda ${ }^{5}$, V. A. Shablii ${ }^{1,2}$

${ }^{1}$ Institute of Molecular Biology and Genetics, NAS of Ukraine 150, Akademika Zabolotnoho Str., Kyiv, Ukraine, 03143

${ }^{2}$ Institute of Cell Therapy, Ministry of Health of Ukraine

3, Lyubomyra Guzara Ave., Kyiv, Ukraine, 03680

${ }^{3}$ Institute of Genetic and Regenerative Medicine, NAMS of Ukraine

67, Vyshgorodska Str., Kyiv, Ukraine, 04114

${ }^{4}$ P. L. Shupik National Medical Academy of Post-Graduate Education

9, Dorohozhytska Str., Kyiv, Ukraine, 04112

${ }^{5}$ Kyiv City Clinical Hospital \# 4

17, Solomianska St, Kyiv, Ukraine, 03110

tahbko@gmail.com

Introduction. Severe Acute Respiratory Syndrome Corona Virus 2 (SARS-CoV-2) causes a coronavirus disease 2019 (COVID-19) characterized by a "cytokine storm" - increased activity of immune cells with the elevated production of inflammatory cytokines leading to respiratory failure. Additionally, the course of pneumonia is characterized by an increased content of $\mathrm{C}$ reactive protein. Leukocytosis, leukopenia and lymphopenia are also commonly present in COVID-19 patients. Fine alterations of the immune cells subpopulations and cytokines level in COVID-19 patients are little known. This work aimed to determine the immunophenotype of peripheral blood cells subpopulations and to study the mentioned underlying changes in IL-6 and CRP levels in patients with COVID-19 pneumonia. Methods. Blood count with Erythrocyte Sedimentation Rate (ESR) was completed by routine blood assay. CRP and IL-6 levels were measured by ELISA. Immunophenotype of subpopulations of peripheral blood cells was acquired by multiparametric fluorescence flow cytometry. Results. Blood parameters comparison in 14 hospitalized severe COVID-19 patients showed that WBC count increased on day 7 and steadily decreased by day 28 , while the percentage of neutrophils decreased gradually from the time of admission to full-recovery state. The percentage and count of lymphocytes regularly increased. The percentage of monocytes had a trend to rising but not statistically significant. The red blood cells count, ESR, and platelet count were not altered during COVID-19 progression. On initial admission, $35.7 \%$ of COVID-19 patients had leucopenia, while $14.3 \%$ of patients had leukocytosis on day 7 . Lymphopenia occurred in $76.9 \%$ of patients on day 0 and was not present on day 28. Changes in CRP levels were statistically significant over the duration of COVID-19 progression and recovery $(\mathrm{p}=0.003 ; \mathrm{n}=15)$. The maximum CRP value was at day 0 but reached a normal range on day 28 . The Il-6 level did not change significantly over 28 days of observation demonstrating a steady twice higher level in COVID-19 patients compared to healthy donors $(p=0.934 ; n=8)$. The population of CD45+ cells was significantly lower in COVID-19 patients than in the healthy donors group $(p=0.009 ; n=12)$. Despite it grew gradually from day 0 to 28 , it did not reach the normal value at full-recovery state. The population of $\mathrm{CD} 3+$ cells was higher than the normal ranges at the first assessment, then dropped on day 7 but return to elevated levels on days 14 and $28(p=0.008 ; n=12)$. Changes in the CD19+ cells count were significantly lower than those of the healthy volunteers during the period of observations $(p=0.007 ; n=12)$. There were decreases in CD16+CD56+ cells counts over each time of assessment compared to healthy donors, but not statistically significant. Conclusion. The understanding of the dynamic changes of lymphocyte populations, cytokines production in COVID-19 patients will provide an in-depth knowledge of the COVID-19 pneumonia progression. 


\title{
Plasminogen interaction with blood cells
}

\author{
T. A. Yatsenko, S. M. Kharchenko \\ Palladin Institute of Biochemistry, NAS of Ukraine \\ 9, Leontovycha Str., Kyiv, Ukraine, 01601 \\ tetyanaa.yatsenko@gmail.com
}

Background. Blood cells are active participants of both blood clotting and fibrinolysis. On the surface of a wide range of cells, there are a number of plasminogen receptors and partner proteins, mediating the involvement of the plasminogen-plasmin system in inflammation, differentiation, cell migration, etc. However, it is not known yet, which plasminogen partner proteins are involved in the regulation of the fibrinolytic process on the surface of blood cells in a blood clot. Aim. The present study focused on the investigation of plasminogen binding to blood cells, comparison of plasminogen activation in the presence of erythrocytes, platelets, and leukocytes and search of potential plasminogen receptors on blood cell membranes. Methods. Blood cells (erythrocytes, platelets, leukocytes) were isolated from healthy donor blood. The effect of native and thrombin-activated blood cells on the activation of plasminogen by tissue-type activator was studied. The binding of plasminogen to native and thrombin-activated blood cells has been studied using immunofluorescent spectroscopy. The interaction of plasminogen with proteins of erythrocyte, leukocyte, and platelet membranes was studied by far-blot analysis. Results. Platelets, leukocytes, and erythrocytes have been shown to be able to bind plasminogen on their surface, but proenzyme activation by tissue type plasminogen activator is mediated only on the surface of platelets and leukocytes. Stimulation of platelets and leukocytes with thrombin results in more intensive plasminogen binding to the cells and higher rate of the proenzyme activation (2-fold and 1.2-fold increase of the rate of reaction in the presence of platelets and leukocytes respectively). There are several proteins on the platelet membranes, the molecular weights of which correspond to PLG-RKT (17 kDa), actin $(42 \mathrm{kDa})$, PAR4 $(40 \mathrm{kDa})$, integrin $\beta 3(100 \mathrm{kDa})$, vitronectin and thrombospondin (over $170 \mathrm{kDa}$ ); on leukocyte membranes only one protein band 15-17 kDa was identified, which is potentially histone $2 \mathrm{~B}$ and/or PLG-RKT; the most likely the partner protein for plasminogen on erythrocyte membranes is TIP49a (55 kDa). Conclusions. Blood cells are able to localize plasminogen during blood clot formation, and platelets and leukocytes play a profibrinolytic role in the clot microenvironment. 


\title{
Analysis of protein coalation in the set of the MCF7 cell lines with selective expression of $\mathrm{S6K1}$ isoforms under oxidative stress conditions
}

\author{
A. V. Bdzhola, O. M. Malanchuk \\ Institute of Molecular Biology and Genetics, NAS of Ukraine \\ 150, Akademika Zabolotnoho Str., Kyiv, Ukraine, 03143 \\ a.bdzhola@gmail.com
}

\begin{abstract}
Aim. The goal of this work was to investigate the change of CoAlation modification in the set of the MCF7 cell lines with selective expression of S6K1 isoforms under oxidative stress and to examine the possibility of involvement of different isoforms of ribosomal protein S6 kinase in these processes. Methods. Previously a novel subset of the immortalized MCF7 human epithelial breast cancer cell lines were developed in our department by utilizing CRISPR/Cas9 to facilitate p85-S6K1, p70-S6K1 and p60-S6K1 knockout. Cell lines with suppressed expression of p85 isoform (MCF7 p85-/p70+/p60+), expression of p60S6K1 alone (MCF7 p85-/ $\mathrm{p} 70-/ \mathrm{p} 60+$ ) and with suppressed expression of all isoforms (MCF-7 p85-/p70-/p60-) were presented in the research. To induce oxidative stress, the cells were treated with $0.5 \mathrm{mM}$ hydrogen peroxide or diamide $(0.5 \mathrm{mM})$ for 30 minutes. Protein CoAlation and S6K1 expression were visualized using western blot analysis and immunofluorescence assay. The detection of protein CoAlation was performed by unique in-house developed specific monoclonal anti-CoA antibodies. Results. In western blot analysis of total cell lysates a slight level of CoAlation was detected in every examined non-treated cell line and higher levels of modification - in cells with induced oxidative stress. Although, no CoAlated proteins were identified as the ribosomal protein S6 kinase 1 isoforms, it was demonstrated that MCF7 wild type cells and MCF7 with expression of p60-S6K1 alone have more significant CoAlation level compared to the rest of examined MCF7 cell lines. Immunofluorescent analysis of subset of MCF7 cell lines revealed the anti-CoA immunoreactive signal in all cell lines even at normal cell growth conditions but with visible enhancement in cells under oxidative stress conditions. Conclusions. Alterations in mTOR/S6K signaling under the CRISPR/Cas9-mediated p85-S6K1, p70-S6K1 and p60-S6K1 knockout in MCF7 cells were revealed. In this work it was not shown that isoforms of ribosomal protein S6 kinase 1 are CoAlated in response to oxidative stress. Nevertheless, the correlation between the expression of specific S6K1 isoforms in the cell and the endogenous CoAlation level was detected. Such observation demonstrates the involvement of S6 kinase 1 isoforms in the process of CoAlation but its role in the process of such modification should be discovered.
\end{abstract}




\title{
Analysis of cell number regulator gene (CNR 12) alleles in Prunus avium and related species
}

\author{
M. O. Valin 1 , Y. O. Tynkevich², R. A. Volkov², Y. I. Ivanovych ${ }^{3}$ \\ ${ }^{1}$ Yuriy Fedkovych Chernivtsi National University \\ 2, Kotsjubynskyi Str., Chernivtsi, Ukraine, 58012 \\ ${ }^{2}$ Department of Molecular Genetics and Biotechnology. Yuriy Fedkovych Chernivtsi National University \\ 2, Kotsjubynskyi Str., Chernivtsi, Ukraine, 58012 \\ ${ }^{3}$ Institute of Horticulture of the National Academy of Agrarian Sciences of Ukraine \\ 23, Sadova Str., Kyiv, Ukraine, 03027 \\ valin.maksym@chnu.edu.ua
}

\begin{abstract}
Aim. In flowering plants, the size and weight of fruits are mainly under the control of CSR (cell size regulator) and $C N R$ (cell number regulator) genes. Among them, the CNR12 gene is the best characterized. In sweet cherries, three allelic variants of this gene were described: PavCNR12-1,-2, and -3, which differ in fourteen SNPs in noncoding regions, particularly in the promoter. These alleles have different effects on the fruit size. Respectively, the presence of a particular allele is an important feature for breeding. Comparative analysis of the promoter sequences of the $C N R$ genes in closely related species of the genus Prunus is necessary to understand the relationship between the promoter structure and fruit size. Currently, data on the organization and occurrence of the CNR12 alleles are available only for a limited number of sweet cherry cultivars. Therefore, our goal was to analyze the sequence of the promoter region of the CNR12 gene and to determine the allelic state of this gene in sweet cherry cultivars and related species. Methods. The samples of genomic DNA of Ukrainian $P$. avium cultivars were provided by the Institute of Horticulture of the NAS of Ukraine. The CNR12-1, -2 and -3 alleles were identified using Tai I SNP-polymorphism in their promoters. The region was amplified by PCR, the amplicons were treated by Tai I restriction endonuclease and the obtained products were analyzed by electrophoretic separation. Applying the SeqMan NGen program, the CNR12 promoter regions were assembled for various sweet cherry cultivars and related species whose genomes are deposited in the sequence read archive (SRA) database. Results. Our data show that the majority of sweet cherry cultivars contain known alleles of the PavCNR12 gene in the homo - (26 cultivars) or heterozygous ( 9 cultivars) states. Most cultivars are homozygous for the PavCNR12-1 allele. For the Bing cultivar, the simultaneous presence of three known alleles was detected, which may indicate triploidy of this sample. Along with this, three alleles containing new SNPs in the promoter region were identified in the genomes of Katafito, Kwar, and F12-01 cultivars. Also, the restriction analysis showed the possible presence of a new allele in the genome of the Ukrainian cultivar Zoryana. Asian species of the s/g Cerasus: P. serrulata and P. sargentii, show high similarity with each other in the sequence of the CNR12 gene promoter, but differ in a significant number of SNPs compared to the PavCNR12 gene. Conclusions. The known alleles PavCNR12-1, $-2,-3$ in the homo - or heterozygous state and three new allelic variants were found in the analyzed sweet cherry cultivars. The CNR12 of Asian species $P$. serrulata and $P$. sargentii differ from PavCNR12 in a large number of SNPs.
\end{abstract}




\title{
Comparative characteristics of expression patterns and fusogenic properties of gallus gallus retroviral env genes
}

\author{
O. V. Zhuk ${ }^{1}$, V. O. Dotsenko², P. O. Areshkov ${ }^{1}$, I. Y. Skrypkina ${ }^{1}$, V. A. Shablii1, \\ ${ }^{1}$ Institute of Molecular Biology and Genetics, NAS of Ukraine \\ 150, Akademika Zabolotnoho Str., Kyiv, Ukraine, 03143 \\ ${ }^{2}$ Institute of Cell Therapy, Ministry of Health of Ukraine \\ 3, Kosmonavta Komarova Ave., Kyiv, Ukraine, 03680 \\ alex.funte@gmail.com
}

Introduction. Retrovirus env genes "captured" in the genome of viviparous ancestors play a critical role in the placenta development of eutherian mammals being involved in the cell-cell fusion and maternal-fetal immune tolerance. In a complex reciprocal interplay with the host the captured genes may undergo different evolutionary fates, playing the role of 'generators of diversity'. Aim. Therefore, it was interesting to identify the possibility of integrating of retrovirus env representatives into the genome of oviparous species and to define their functional significance for the development of the embryo outside the mother's body. Methods. The search for the retroviral env genes was carried out in the Gallus gallus genome assembly V5.0 ( NCBI database). All open reading frames (ORF) longer than $450 \mathrm{bp}$ were selected from downloaded genomic sequences using Unipro UGENE 1.30 and checked against the HMM model of TLV-coat motif. Then all TLV-contained ORFs were checked for containing the canonical Env domains and motives using HMM search. The predicted env's were obtained by PCR and cloned into pGEMT-Easy and phCMV-VSVG vectors for further research. All sequences were confirmed by sequencing. WISH was performed with the corresponding DIGlabelled RNA probes. Determination of the results of transfection of eukaryotic cells was performed by fluorescent immunohistochemistry. Expression of the putative G. gallus env genes in embryonic chicken myocytes was studied by qPCR. Results. We identified the endogenous retroviral env genes in G. gallus the proteins of which have all the canonical structural characteristics of the syncytins. They have common specific expression in the extra embryonic membranes, derma myotome, notochord, pharynx, and heart in the chicken embryo until 3 days of development. The chicken env genes have a similar intracellular localization comparing to human syncytin-1, and their overexpression leads to the cell-cell fusion of different cell lines, such as HEK 293T, DF-1, MEF-1. After the induction of differentiation and fusion of embryonic leg buds-derived myocytes in vitro, the ALV expression decreases sharply. Instead, the level of ALV expression in the leg buds from 4 to 10 days of development was higher at E5 stage when the active processes of somite mesoderm cell migration and fusion are observed. Conclusions. We have shown that the genes of the G. gallus endogenous retrovirus env are expressed in various embryonic tissues and in extra embryonic membranes. Chicken Env's superbly induce the cell-cell fusion in the eukaryotic cultures of various origins. Moreover, they were detected in the migrating neural crest derived mesenchymal cells and in the derma-myotome cells. However, we did not find fusogenic activity of the chicken env genes, at least in embryonic myocytes, because the high level of their expression is maintained only in undifferentiated migrating cells. It can be assumed that they are involved in other cellular processes, such as migration or proliferation. 


\title{
Obtaining of transgenic broccoli plants producing recombinant interferon alpha-2b protein
}

\author{
Y. M. Prokhorova \\ Institute of Cell Biology and Genetic Engineering, NAS of Ukraine \\ 148, Akademika Zabolotnogo Str., Kyiv, Ukraine, 03680 \\ prokhorova.lisa@gmail.com
}

Cancer is a second cause of death in Ukraine and the number of cases reaches 70 thousand people a year. Human interferon $\alpha-2 b$, which belongs to the large family of interferons, regulates the expression of genes involved in the antiproliferative and antiviral activity. Recombinant interferon is FDA approved therapeutic protein and used in treatment of some types of cancer. Broccoli (Brassica oleracea L. var. italica) is an important vegetable crop which is nutrientrich and also contains sulforaphane - an effective antioxidant known by its anti-tumor activity. The aim of our work was to obtain transgenic broccoli plants expressing the inf $\alpha-2 b$ gene for the anticipated increasing of the anticancer properties of this plant. Methods. Broccoli plants cv. Vitaminna were selected for this work. The aseptic broccoli seedlings obtained by surface sterilization of seeds were used as plant material for genetic transformation. It was realized by co-cultivation in liquid B5 medium of $1 \mathrm{~cm}$ hypocotyl explants and Agrobacterium tumefaciens strain GV3101 carrying pCB124 or pNPB029 vector constructs which both contain the inf $\alpha-2 b$ gene sequence. Then explants were incubated for 48 hours in B5 culture medium supplemented with growth regulators $3.5 \mathrm{mg} / 1 \mathrm{BA}, 0.02 \mathrm{mg} / \mathrm{l} \mathrm{NAA}$ and for increasing the transformation frequency $-100 \mathrm{mM}$ acetosirengone. For shoot formation the explants were transferred to the same regeneration medium supplemented with $5 \mathrm{mg} / \mathrm{l}$ phosphinotricin or $20 \mathrm{mg} / \mathrm{l} \mathrm{kanamycin}$ as a selective agent (depends on the vector constructions that were used) and also $500 \mathrm{mg} / \mathrm{l}$ ceftriaxonum for bacterial elimination. After 5-6 weeks of cultivation, green shoots of $1-2 \mathrm{~cm}$ in size were formed at the sites of thickening of hypocotyl explants. The selected plants were transfered to growth regulators-free medium for the root formation. The leaves of the obtained plants were used for total DNA extraction by the CTAB method. PCR analysis with primers specific for the target genes confirmed the presence of the inf $\alpha$ - $2 b$ gene in the genome of obtained transgenic broccoli plants. As a result, transgenic broccoli plants cv. Vitaminna were obtained by agrobacterium transformation. The presence of a transgenic insert of the recombinant inf $\alpha-2 b$ gene in the obtained plants was confirmed by a molecular biological analysis. Next we plan to analyze the antiproliferative and antiviral activity of the interferon $\alpha-2 b$ protein in the plant extracts. Conclusions. So the broccoli plants cv. Vitaminna were introduced into the in vitro culture by surface sterilization of seeds. The optimal concentration of growth regulators was selected for this crop and a maximum regeneration rate of 62 percent was achieved. PCR analysis confirmed the presence of the interferon gene sequence in the kanamycin or phosphinotrycin-resistant broccoli plants. 


\title{
Phylogenetic analysis of $\mathrm{HCB}$-resistant soil bacteria
}

\author{
M. I. Dimova, L. A. Dankevych, N. A. Yamborko \\ D. K. Zabolotny Institute of Microbiology and Virology, NAS of Ukraine \\ 154, Academika Zabolotnogo Str., Kyiv, Ukraine, 03680 \\ mdildiv@gmail.com
}

Introduction. Due to the active and long-term using in the agro-industrial complex of organochlorine pesticides, which include hexachlorobenzene (HCB), the soil condition has undergone negative changes. Members of the genus Comamonas are known to be promising for the bioremediation measures to restore ecosystems. The isolation and identification of new bacterial strains with a potential to destroy xenobiotics is relevant. The aim of the study was to establish the taxonomy position of two strains of soil bacteria isolated from the landfill of organochlorine pesticides by sequencing the 16S rRNA gene. Methods. DNA was isolated by the express method. Amplification of the 16S rRNA gene was performed by using universal bacterial primers pA-5'-AGAGTTTGATCCTGGCTCAG-3 ' $(8-27$, E. coli numbering) and pH-3'-AAGGAGGTGATCCAGCCGCA-5' (1542-1523, E. coli numbering). 16S rRNA sequences were analyzed on an automatic sequencer 3130 Genetic Analyzer (Applied Biosystems / HITACHI) using a set of BigDye Terminator v3.1 Cycle Sequencing kit (Applied Biosystems). Nucleotide sequences of 1437 n.p. (strain \# 46) and 1487 n.p. (strain \# 47) were obtained. To establish the affinity of the 16S rRNA gene nucleotide sequences of the studied strains with homologous sequences of typical strains of the families Comamonadaceae, Burkholdereaceae and Pseudomonadaceae, placed in GenBank, the BLAST program was used. Dendrograms of nucleotide sequence affinity were constructed by the Neighbor Joining method using a two-parameter Kimura's model based on 100 replicates of the bootstrap assay. Results. The comparison of the 16S rRNA genes nucleotide sequences of isolated strains and deposited sequences of this gene in members of the families Comamonadaceae, Burkholdereaceae and Pseudomonadaceae showed the highest similarity with the members of the family Comamonadaceae. Phylogenetic analysis showed that the affinity for C. testosteroni LMG 1800 of strain \# 47 was $98.05 \%$, and of strain \# 46-97.77\%, which gives reasons to classify it as C. testosteroni. Conclusions. According to the complex of molecular-genetic and physiological-biochemical characteristics, the strains \# 46 and \# 47 are classified to Comamonas testosteroni. 


\title{
Improved pipeline for differential gene expression analysis in human placenta from preeclamptic and normotensive pregnancy
}

\author{
S. V. Zubenko, O. K. Lykhenko, A. O. Frolova, M. Yu. Obolenska \\ Institute of Molecular Biology and Genetics, NAS of Ukraine \\ 150, Akademika Zabolotnoho Str., Kyiv, Ukraine, 03143 \\ s.v.zubenko@imbg.org.ua
}

Background. The multifactorial pregnancy complications with placental dysfunction as a pivotal cause of disease require a fast and reliable pipeline for data analysis obtained by nextgeneration RNA sequencing (NGS). Aim. The study explores the efficiency of the elaborated pipeline for identifying differentially expressed genes (DEGs) starting from raw RNA-seq data. Methods. The raw gene expression data obtained by NGS (Illumina Hiseq 2500) were from 32 and 33 placental cases and control placental samples, correspondingly [Ren et al., 2021]. We conducted quality control and preprocessing of FASTQ files, the intermediate output files after NGS, by an ultra-fast all-in-one FASTQ preprocessor, fastp [Chen et al., 2018]; the reads mapping against the human genome assembly GRCh38.p13; the alignment and expression counting by the sliced transcripts alignment to a reference (STAR) software [Dobin et al., 2012]; normalizing gene expression by variance stabilizing transformation (VST). We divided samples according to the sex using XIST gene as a marker; differentially expressed protein-coding genes were identified by the R package DEseq2 [Love et al., 2014] and the Ensembl database. We used the String database to build the network of protein-protein interactions corresponding to DEGs; a fastgreedy algorithm [He et al., 2006] to identify clusters in the network; Gene Ontology to characterize the biological processes involving genes from each cluster, and the Human Protein Atlas to determine the cell-specificity of the differentially expressed genes. Results. We have identified 1296 DEGs vs. 1291 found in the original paper, out of which 983 DEGs $(76 \%)$ are in common. The possible source of the difference is that we have taken into account fetal sex during DEGs identification. We revealed three major clusters of DEGs reflecting tissue and organ development, angiogenesis and immune response, and metabolism. The first cluster includes the genes associated with nervous system development and function due to the multifunctionality of proteins or placental proteins secretion affecting maternal and fetal nervous systems like leptin. The second cluster contains the genes involved in angiogenesis, killing cells of other organisms, myeloid cell apoptosis, which could reflect the disrupted mother-fetus immune balance. The third cluster features the genes that take part in metabolic processes in response to oxidative stress, e.g., CYP1A1 and CYP1A2. Unlike the pipeline in the original study, we have used fastp and STAR software and considered the fetal sex for DEGs identification. Conclusions. Our results are consistent with the original study, which validates the proposed pipeline. Taking fetal sex into account extends the DEGs amount compared to the original research. 


\title{
Bioinformatic analysis of the 5S rDNA IGS in the honeybee Apis mellifera caucasica
}

\author{
N. M. Roshka, R. A. Volkov \\ Yuriy Fedkovych Chernivtsi National University \\ 2, Kotsjubynskyi Str., Chernivtsi, Ukraine, 58012 \\ n.roshka@chnu.edu.ua
}

\begin{abstract}
Aim. In the recent decade, a massive bee colonies loss was observed all over the world. One of the reasons for this is believed to be the loss of local breeds/subspecies of the honey bee. To identify subspecies and monitor genetic diversity in populations of honey bee the application of molecular markers is required. Due to the high rate of molecular evolution, the $5 \mathrm{~S}$ rDNA intergenic spacer (IGS) region represents a convenient source of molecular markers, which can be used to distinguish closely related forms of plants and animals. In our study, we performed bioinformatic analysis of the sequenced A. $m$. caucasica genome in order to identify repeated units of 5S rDNA and asses their diversity. Methods. A sequenced genome of $A$. $m$. caucasica was analyzed. Scaffolds containing $5 \mathrm{~S}$ rDNA repeats were found using the BLAST algorithm. 5S rDNA repeated units within the selected areas were identified by homology to 5S rRNA coding region and collected with Lasergene software package (DNASTAR). The obtained IGS sequences were aligned by the Clustal V method. The ML phylogenetic tree was constructed using the IQTree web server. Results. BLAST search inside the whole genome allowed us to find the 5S rRNA coding regions in five scaffolds, one of which (JACDQY010000059.1) was selected for further analysis. Applying the software package Lasergene, we identified 20 IGS sequences. The alignment of these sequences demonstrated a high level of similarity ( $85-100 \%$ ), despite the presence of several indels (insertions/deletions). Within the IGS, we also found potential regulatory elements that can participate in the 5S rDNA transcription. These elements are represented by TATA-like (TATTT) and oligo-T motives, which are probably involved in the transcription initiation and termination, respectively. On the phylodendrogram, the IGS sequences identified by us were grouped into five clades, indicating that at least five variants of IGS exist in the genome of the $A$. $m$. caucasica. Conclusions. The bioinformatics analysis of the 5S rDNA IGS sequences of A. m. caucasica showed a clear distribution into several distinct classes. Presumably, five different variants of 5S rDNA IGS exist in the genome of the Caucasian bee.
\end{abstract}




\title{
The influence of biostimulators based on Streptomycetes on growth and development of tomato
}

\author{
A. Yu. Buziashvili1 ${ }^{1}$ L. O. Biliavska ${ }^{2}$, G. O. Iutynska' ${ }^{2}$ A. I. Yemets ${ }^{1}$ \\ ${ }^{1}$ Institute of Food Biotechnology and Genomics, NAS of Ukraine \\ 2A, Osipovskogo Str., Kyiv, Ukraine, 04123 \\ ${ }^{2}$ D. K. Zabolotny Institute of Microbiology and Virology, NAS of Ukraine \\ 154, Academika Zabolotnogo Str., Kyiv, Ukraine, 03680 \\ buziashvili.an@gmail.com
}

\begin{abstract}
Aim. Investigation of the influence of microbial biostimulators Avercom and Avercom Nova on the length of shoots and roots, fresh mass and total protein content in seedlings of tomato cultivars Money Maker and Lahidny. Methods. Tomato seedlings were cultivated in vitro on MST medium (4.3 mg/l of micro — and macrosalts MS (Murashige and Skoog, 1962), $100 \mathrm{mg} / \mathrm{l}$ myo-inositol, $0.5 \mathrm{mg} / \mathrm{l}$ nicotinic acid, $0.5 \mathrm{mg} / \mathrm{l}$ pyridoxine, $1 \mathrm{mg} / \mathrm{l}$ thiamine, $2 \mathrm{mg} / \mathrm{l}$ glycine, $30 \mathrm{~g} / 1$ sucrose, $8 \mathrm{~g} / \mathrm{l}$ agar, pH 5.7) supplemented with 25, 50, 75, $100 \mu \mathrm{l} / 1$ of biostimulators Avercom and Avercom Nova. The length of shoots and roots of 10 - and 14-day-old seedlings was measured with the use of ImageJ software (https://imagej.nih.gov/ij/). The concentration of total protein in shoots of tomato seedlings was measured according to the Bradford method. Results. It was shown that Avercom at concentration $25 \mu 1 / 1$ increases the length of shoots and roots of tomato cv Lahidny after 10th day of cultivation up to 5.26 and $5.81 \mathrm{~cm}$. The highest values of the length of shoot of 10-day-old seedlings of tomato cv Money Maker were observed in the presence of $75 \mu \mathrm{l} / 1$ of preparation Avercom $(4.92 \mathrm{~cm})$, and the highest length of roots $(5.21 \mathrm{~cm})$ was observed after the addition of $75 \mu 1 / 1$ of Avercom Nova into the medium. At the 14th day of cultivation, the maximum length of shoots and roots of tomato cv Lahidny was detected in the presence of $25 \mu \mathrm{l} / 1$ of Avercom Nova $-6.94 \mathrm{~cm}$ and $10.29 \mathrm{~cm}$, respectively. The maximum length of shoots $(6.24 \mathrm{~cm})$ and roots $(7.18 \mathrm{~cm})$ of tomato cv Money Maker was identified in the presence of $25 \mu \mathrm{l} / \mathrm{l}$ Avercom and $25 \mu \mathrm{l} / \mathrm{l}$ Avercom Nova. It was established that both preparations Avercom and Avercom Nova enhance the fresh mass of tomato seedlings at concentration of $25 \mu \mathrm{l} / \mathrm{l}$. The highest mass of the seedlings of tomato $\mathrm{cv}$ Lahidny at the 10th day of cultivation $(73.4 \mathrm{mg})$ and at the 14th day of cultivation $(93.8 \mathrm{mg})$ was observed in the presence of Avercom, whereas the highest mass of the seedlings of tomato cv Money Maker at the 10th $(42.9 \mathrm{mg})$ and at the 14th day $(48.2 \mathrm{mg})$ was identified in the presence of Avercom Nova. The highest total protein content in tomato seedlings was established after the addition into the MST medium of both Avercom and Avercom Nova at concentration of $50 \mu \mathrm{l} / \mathrm{l}$. For tomato cv Lahidny the highest total protein content $(18.5 \mathrm{mg} / \mathrm{g}$ of fresh mass at the 10th day of cultivation and $28.8 \mathrm{mg} / \mathrm{g}$ at 14th day of cultivation) was detected in the presence of Avercom Nova. As for the seedlings of tomato cv Money Maker, the maximum content of total protein after 10 and 14 days of cultivation were $11.99 \mathrm{mg} / \mathrm{g}$ and $13.29 \mathrm{mg} / \mathrm{g}$ of fresh mass, respectively, in the presence of Avercom Nova. Conclusions. The biostimulators based on plant growth-promoting Streptomycetes Avercom and Avercom Nova could be the promising alternative to chemical fertilizers and pesticides as they promote the growth of shoots and roots, enhance the fresh mass and total protein content in tomato seedlings.
\end{abstract}




\title{
Investigation of effectiveness of MGMT potential inhibitors in human cell cultures
}

\author{
K. S. Zhuvaka, A. P. Iatsyshyna, Z. M. Nidoeva, G. P. Volynets, T. P. Ruban, \\ L. L. Macewicz, S. M. Yarmoluk, L. L. Lukash \\ Institute of Molecular Biology and Genetics, NAS of Ukraine \\ 150, Akademika Zabolotnoho Str., Kyiv, Ukraine, 03143 \\ Kateopryshko@gmail.com
}

\begin{abstract}
Aim. The purpose of this work is to investigate a number of new low molecular weight nonnucleoside compounds as potential inhibitors of MGMT. Those compounds have been selected to study their influence on the MGMT gene expression at protein level by Western blot analysis. Evaluation of their effects in tumor Hep-2 cells will allow a more accurate assessment of their effectiveness as potential inhibitors comparing to O6-benzylguanine. Methods. In the first stage, Hep-2 cells have been cultivated in the standard medium DMEM containing one of tested compounds at a concentration of $10 \mathrm{~nm}$ with and without alkylating agent nitrosoguanidine at different concentrations. In the second step, proteins were extracted from the isolated Hep-2 cells and their concentration was measured with a NanoDrop 2000/2000c Spectrophotometers for Western blot analysis. The obtained results have been analyzed in the programs Origin8.1 and ImageLab. Results. We have observed such a general trend: a corresponding gradation of MGMT amounts in variants of the experiment where no inhibitor has been added but only nitrosoguanidine at different doses was present. The amount of MGMT is minimal at the highest concentration of nitrosoguanidine, $50 \mu \mathrm{g} / \mathrm{ml}$, which reveals own toxic effect in the cells, and the amount of MGMT is maximal and even bigger than in adequate control at the concentration of alkylating agent $-0,5 \mu \mathrm{g} / \mathrm{ml}$. So, probably, nitrosoguanidine is able to stimulate the expression of $M G M T$ at small concentrations which is consistent with the literature data. We have received some data which show that new potential inhibitors at the concentration of $10 \mathrm{nM}$ are able to decrease the expression of $M G M T$ gene in the cells in vitro. In combination of potential inhibitors with nitrosoguanidine at the concentration $0.5 \mu \mathrm{g} / \mathrm{ml}$, a decrease of MGMT amounts has been observed relatively to the control. It has been observed even greater decrease in MGMT level for each combination of potential inhibitor with nitrosoguanidine at the concentration of $50 \mu \mathrm{g} / \mathrm{ml}$ relatively to the same control. Thus, another general trend is that the combination of one of tested potential inhibitors with nitrosoguanidine reduces the amount of MGMT in the cells. The higher concentration of nitrosoguanidine in combination with the inhibitor $(C=10 \mathrm{nM})$, the less amount MGMT in the cells is determined in the experiment. Conclusions. There is an observation that nitrosoguanidine at relatively small concentrations stimulates the expression of $M G M T$ gene in Hep-2 cells in vitro. Our data show that new potential inhibitors at concentration of $10 \mathrm{nM}$ are able to decrease the expression of $M G M T$ gene at protein level. The combination of tested potential inhibitors with nitrosoguanidine reduces the amount of MGMT and the higher concentration of nitrosoguanidine the less amount of MGMT in the cells is oserved.
\end{abstract}




\title{
Autophagy as an adaptive response to draught in Triticum aestivum
}

\author{
S. H. Plokhovska, N. O. Pushkarova, Ya. B. Blume, A. I. Yemets \\ Institute of Food Biotechnology and Genomics, NAS of Ukraine \\ 2A, Osipovskogo Str., Kyiv, Ukraine, 04123 \\ svetaplohovska@gmail.com
}

Background. Autophagy is a catabolic process of damaged organelles, cytoplasm fragments, denatured or aggregated proteins undergoing intracellular degradation (Chen et al., 2019). Plant autophagy is involved in numerous cell processes providing homeostasis and plant growth and development (Liu et al., 2009; Lv et al., 2014). Under stress condition such as drought additional autophagy induction is issued for the cells energy and biosynthetic needs providing and damaged proteins disposal (Zhang et al., 2020). The upregulation of ROS is one of the universal plant reactions on stress influence which could lead to its accumulation and oxidative stress induction. Oxidative stress is a powerful autophagy inductor in eukaryotic cells. The aim of this research was to study drought stress autophagy in wheat. Methods. For autophagosome detection in spring wheat cells (Zlata cultivar) fluorescent dye LysoTracker Red was used as it specifically binds with autophagosomes and helps to identify these intracellular structures in living cells. The study was performed on 6th and 9th day of growth under drought stress that was modulated by $10 \%$ of 6000 polyethylene glycol (PEG) addition to the growth medium. Fluorescence in root cells was studied using LSM 510 META laser scanning confocal microscope (Carl Zeiss, Germany) with an argon laser (647 nm wavelength), Plan-Neofluar 40x/1.30 Oil DIC lens. All studies were performed in at least three replicates. Results. Starting from the 6th day of cultivation under drought stress the appearance of colored point structures $1 \mu \mathrm{m}$ and larger in size, which correspond to autophagosomes, were observed. This phenomenon was identified as reproducible in several repeated experiments which indicates this feature as a stress induced reaction. It should be noted that the number of autophagosomes on the 6th day of cultivation for epidermal cells of transition zone increased comparing to control (plant growth without drought stress influence). On the 9th day of cultivation under stress conditions the number of autophagosomes decreased compared to the 6th day cultivated root cells although it was still higher than in the control plants. Temporary autophagy induction and its gradual decrease could indicate the wheat root cells adaptation to the drought stress influence. Conclusions. The obtained results indicate autophagy adaptive role in the response to drought. At the same time, these results provide a basis for molecular genetic mechanisms of stress induced autophagy development. 


\title{
Treatment of acute pancreatitis in rats using MSCs of the human umbillical cord
}

\author{
P. O. Pikus ${ }^{1,2}$, A. V. Rudenko ${ }^{1}$, Y. M. Reshetnik ${ }^{3}$ \\ ${ }^{1}$ Institute of Molecular Biology and Genetics, NAS of Ukraine \\ 150, Akademika Zabolotnoho Str., Kyiv, Ukraine, 03143 \\ ${ }^{2}$ Institute of Genetic and Regenerative Medicine, NAMS of Ukraine \\ 67, Vyshgorodska Str., Kyiv, Ukraine, 04114 \\ ${ }^{3}$ Educational and Scientific Center "Institute of Biology and Medicine", \\ Taras Shevchenko National University of Kyiv \\ 64/13, Volodymyrska Str., Kyiv, Ukraine, 01601 \\ polinaignatchenko7@gmail.com
}

Background. Acute pancreatitis (AP) is serious disorder requiring emergency hospitalization. After pancreatic tissue necrosis and multiple organ failure in AP, a mortality rate is up to $30-47 \%$. There are currently no effective therapies for AP. MSCs can be a potential candidate for the treatment of this disease due to their immunomodulatory properties. The aim of this study was to compare the therapeutic effect of the transplantation of free MSCs and MSCs preconditioned with $\mathrm{H}_{2} \mathrm{O}_{2}$ in the rat model of AP. Methods. Wistar rats were randomized into four groups: a negative control group received normal saline; a positive control group obtained the intraperitoneal injection of L-arginine at a dose of $200 \mathrm{mg} / 100 \mathrm{~g}$ of body weight within $1 \mathrm{~h}$ interval in-between; and two of experimental groups were injected intraperitoneally with free MSCs of human umbilical cord and preconditioned MSCs with $30 \mu \mathrm{mol} \mathrm{H}_{2} \mathrm{O}_{2}$ second passage at a dose $\left(6-7 \times 10^{6}\right.$ cells $/ \mathrm{kg}$ of rat weight) $24 \mathrm{~h}$ after AP induction. Rats were sacrificed after 7 days, the pancreatic tissues and blood were collected. Biochemical and histological methods were used to determine the amylase level and pathological changes in the rat pancreas. Results. One day after the AP induction, the amylase level increased by 7 times, and histological analysis indicated acute organ damage. The size of fibrotic area was 5 times larger than the negative control. The similarly important morphometric parameter was the presence of a large number of non-nuclear acinar cells and infiltration of inflammatory cells. 7 days after transplantation of free MSCs and MSCs preconditioned with $\mathrm{H}_{2} \mathrm{O}_{2}$ into the rats with induced AP, the amylase level in the blood of rats decreased 2 times after MSC transplantation, and decreased 3 times after injection of preconditioned MSCs. The size of fibrotic area in the pancreatic parenchyma was decreased by 3.5 times after MSC transplantation and almost returned to norm after the injection of MSCs preconditioned with $\mathrm{H}_{2} \mathrm{O}_{2}$. Other morphometric parameters of pancreas almost return to a normal level. Conclusions. The results of this study show that the transplantation of free MSCs to the rats with modeling acute pancreatitis led to the recovery of structural and functional parameters, but the injection of preconditioned MSCs with $30 \mu \mathrm{mol} \mathrm{H}_{2} \mathrm{O}_{2}$ significantly improved the therapeutic efficacy of MSC therapy. 


\title{
The effect of the chemotherapeutic drug temozolomide on glioma cells in primary culture, individual sensitivity to the drug
}

\author{
I. M. Shuba1, N. P. Oleksenkoํ, V. V. Lylo², I. S. Karpova², M. M. Shevelov, \\ O. Ya. Glavatskyi ${ }^{1}$ \\ ${ }^{1}$ SI "A. P. Romodanov Institute of Neurosurgery NAMS of Ukraine" \\ 32, Platona Mayborody Str., Kiev, 04050 \\ 2 Institute of Molecular Biology and Genetics, NAS of Ukraine \\ 150, Akademika Zabolotnoho Str., Kyiv, Ukraine, 03143
}

Background. Glioblastoma is the most common malignant primary brain tumor in adults, which has an extremely unfavorable prognosis and is characterized by the lowest survival rates. The drugs that have shown the greatest effectiveness in the treatment of this pathology include temozolomide (TMZ) with an alkylating mechanism of action. Resistance of malignant glial tumors to antitumor therapy with this drug is associated with high levels of gene expression of the repair enzyme $\mathrm{O}^{6}$-methylguanine-DNA methyltransferase (MGMT). Therefore, determination of the status of the MGMT gene (presence / absence of hypermethylation of the gene promoter) in glioma cells is necessary when prescribing temozolomide mono-chemotherapy according to the Stupp protocol for glioblastoma (2005 edition). The aim. To investigate the effect of the alkylating chemotherapeutic drug TMZ on glioma cells in primary culture obtained from tumor fragments, to assess individual sensitivity to the drug. To check the effect of different concentrations of temozolomide on the gliomas cells line U251MG in order to select possible effective doses of the drug. Methods. The hypermethylation status of the gene promoter that correlates with the level of $M G M T$ gene expression was determined by classical PCR. Primary cells were extracted directly from the tumor tissue and processed to establish under culture conditions. Cultivation was carried out in a medium DMEM with the addition of $10 \%$ embryonal veal serum (Sigma, USA) in a $\mathrm{CO}_{2}$ incubator (ES-160 "Nüve", Turkey) under standard conditions ( $\mathrm{t}=37^{\circ} \mathrm{C}, 5 \%$ $\mathrm{CO}_{2}$ ). The concentration of TMZ in the incubation medium was $250 \mu \mathrm{M}$ (corresponding to the dose of $200 \mathrm{mg} / \mathrm{kg}$, taking into account the coefficient of body surface, according to the clinical protocol). U251MG transplantation cells were treated with TMZ at a concentrations of $16 \mathrm{nM}$ to $13 \mathrm{mM}$. The cytostatic and cytotoxic effects of TMZ were studied using of $4 \%$ trypan blue. The viability of cells counting the number of cells was performed using a light microscope and a camera Goryaev, counting the percentage of living and dead cells. Results. In 6 cases in the primary culture, when of the MGMT gene expression was available, the percentage of living cells relative to the control after incubation with TMZ ranged from $63.9 \%$ to $94.9 \%$. The remission period in this group of patients ranged from 3 to 16 months. In the group of samples in the absence of $M G M T$ gene expression (4 cases), the percentage of living cells relative to the control ranged from $40.0 \%$ to $82.7 \%$, different remission times were observed in the group of these patients. Only in one case at a low level of living cells (40\%) a maximum remission of 28 months was observed. In experiments with the U251MG cells the concentrations of the temozolomide in the incubation environment ranged from $10 \mathrm{nM}$ to $1.3 \mathrm{mM}$. It was shown a decrease in the total number of cells relative to the control in the range of TMZ concentrations from $10.3 \mu \mathrm{M}$ to $257.5 \mu \mathrm{M}$. Conclusions. It was generally accepted that the efficacy of chemotherapeutic drug TMZ depends on the status of the MGMT gene (presence / absence of expression), but our tests in primary cell culture have shown that the effect of TMZ did not always correlate with the status of the MGMT gene. It indicates on the individual sensitivity / resistance to the drug for these patients and the opportunity of another mechanism that influences the resistance to TMZ. In tests with U251MG cells there was observed a slight cytotoxic effect and a more pronounced cytostatic effect directly proportional to the concentration of TMZ in doses from $10.3 \mu \mathrm{M}$ to $257.5 \mu \mathrm{M}$. 